\title{
Automatic Tracking and Characterization of Cumulonimbus Clouds from FY-2C Geostationary Meteorological Satellite Images
}

\author{
Yu Liu, ${ }^{1,2}$ Du-Gang Xi, ${ }^{3}$ Zhao-Liang Li, ${ }^{4,5}$ and Chun-Xiang Shi ${ }^{6}$ \\ ${ }^{1}$ Institute of Geographic Sciences and Natural Resources Research, Chinese Academy of Sciences, Beijing 100101, China \\ ${ }^{2}$ Institute of Remote Sensing and Digital Earth, Chinese Academy of Sciences, Beijing 100101, China \\ ${ }^{3}$ The PLA Information Engineering University, Zhengzhou 450001, China \\ ${ }^{4}$ Key Laboratory of Agri-Informatics, Ministry of Agriculture/Institute of Agricultural Resources and Regional Planning, \\ Chinese Academy of Agricultural Sciences, Beijing 100081, China \\ ${ }^{5}$ ICube, UdS, CNRS, 300 boulevard Sebastien Brant, CS 10413, 67412 Illkirch, France \\ ${ }^{6}$ National Meteorological Information Center, China Meteorological Administration, Beijing 100081, China
}

Correspondence should be addressed to Zhao-Liang Li; lizl@igsnrr.ac.cn

Received 21 March 2014; Revised 2 August 2014; Accepted 8 August 2014; Published 31 August 2014

Academic Editor: Ismail Gultepe

Copyright (C) 2014 Yu Liu et al. This is an open access article distributed under the Creative Commons Attribution License, which permits unrestricted use, distribution, and reproduction in any medium, provided the original work is properly cited.

\begin{abstract}
This paper presents an automated method to track cumulonimbus $(\mathrm{Cb})$ clouds based on cloud classification and characterizes $\mathrm{Cb}$ behavior from FengYun-2C (FY-2C). First, a seeded region growing (SRG) algorithm is used with artificial neural network (ANN) cloud classification as preprocessing to identify consistent homogeneous $\mathrm{Cb}$ patches from infrared images. Second, a crosscorrelation-based approach is used to track $\mathrm{Cb}$ patches within an image sequence. Third, 7 pixel parameters and 19 cloud patch parameters of $\mathrm{Cb}$ are derived. To assess the performance of the proposed method, 8 cases exhibiting different life stages and the temporal evolution of a single case are analyzed. The results show that (1) the proposed method is capable of locating and tracking $\mathrm{Cb}$ until dissipation and can account for the eventual splitting or merging of clouds; (2) compared to traditional brightness temperature (TB) thresholds-based cloud tracking methods, the proposed method reduces the uncertainty stemming from TB thresholds by classifying clouds with multichannel data in an advanced manner; and (3) the configuration and developmental stages of $\mathrm{Cb}$ that the method identifies are close to reality, suggesting that the characterization of $\mathrm{Cb}$ can provide detailed insight into the study of the motion and development of thunderstorms.
\end{abstract}

\section{Introduction}

In the tropics and midlatitudes, cumulonimbus $(\mathrm{Cb})$ clouds are associated with intense convection and severe weather such as wind gusts, heavy precipitation, lightning, and eventually hail, microbursts, and tornadoes. Their presence may pose a serious risk to aviation and may impact crops and urban populations because rapidly changing weather on various spatial and temporal scales may occur within and near $\mathrm{Cb}$ clouds. Observations of $\mathrm{Cb}$ can be an important source of data for assimilation in weather forecasting and for monitoring climate trends [1].
Geostationary satellite images have been proven to be an important source of observations of dynamic weather events. They are especially useful for convective cloud tracking, thanks to their high temporal resolution and large field of view compared to that of Doppler radars and atmospheric profilers $[2,3]$. The determination of characteristics of $\mathrm{Cb}$ based on cloud tracking from geostationary imageries may improve existing precipitation estimation and nowcasting schemes.

The identification and monitoring of cloud began with manual tracking, such as the work of Martin and Schreiner [4], Rowell and Milford [5], and Fritsch and colleagues 
[6-9]. Those studies are labor intensive and somewhat subjective despite the great improvement in the understanding of the diurnal phases of large convective cloud systems (CS). With the development of faster computers and the introduction of image-processing methods, families of automatic tracking techniques were used, such as the procedure based on a propagation speed criterion by Woodley et al. [10], the algorithm to locate winter monsoon cloud clusters by Williams and Houze [11], the automatic method of tracking clouds with cold tops in African convective systems by Arnaud et al. [12], the algorithm to monitor mesoscale convective systems (MCSs) in Greece by Feidas and Cartalis [13], the Maximum Spatial Correlation Tracking Technique (MASCOTTE) by Carvalho and Jones [14], the Cloud-Top Cooling Rate (CTC) algorithm by the University of Wisconsin [15], and Rapid Developing Thunderstorm (RDT) by Météo-France [16]. Almost all these cloud tracking methods employ the infrared (IR) brightness temperature (TB) threshold principle [17]. However, for $\mathrm{Cb}$ detection, determination of the TB threshold in satellite scenes is a difficult task complicated by spatially and temporally varying surface reflectivity of underlying land surface, complex multilayer cloud structures, and highly variable water vapor content. Thus, neither static thresholds nor climatologically based thresholds are likely to produce robust $\mathrm{Cb}$ detection in any given scene. The problem often is further complicated by sensor-related issues due to multiple layers of cloud moving at different speeds and in different directions.

Up to now, there are numerous literatures documented on severe storms characters $[18,19]$, such as the variation of shooting tops [20-23], the diagnosis/nowcast of convective initiation (CI) [24-28], the formation of MCSs and mesoscale convective complexes (MCCs) [13, 14, 29-31], cloud microphysical processes [32], and the variation of intense convection [33-38]. And a lot of papers have been written concerning characteristics of $\mathrm{Cb}$, such as the dynamical variation of $\mathrm{Cb}[38,39]$ and predictability of evolution [40]. Yet, they are mainly based on cloud numerical models and much less on satellite data. The dedicated study to track $\mathrm{Cb}$ from geostationary imagery is Cumulonimbus Tracking and Monitoring (Cb-TRAM) by Zinner et al. [41], which uses a pyramidal image matcher and a convective cloud mask from ECMWF tropopause temperature data as an adaptive detection criterion. The $\mathrm{Cb}$ detection is essentially based on a climatological threshold principle. Therefore, a more comprehensive multichannel method of cloud classification may help to identify the temporal evolution and spatial properties of convective clouds that cannot be properly investigated with single channel threshold techniques.

A number of cloud classification methods have been developed for remote-sensing instruments using various techniques, such as neural networks [42], clustering analysis [43], maximum likelihood analysis [44], and fuzzy logic [45]. According to previous studies, a neural network classifier usually performs well if it is well trained [46]. In this study, a neural network classifier is used to cluster cloud pixels with similar spectral properties based on three infrared (IR) channels (IR1, 10.3-11.3 $\mu \mathrm{m}$; IR2, 11.5-12.5 $\mu \mathrm{m}$; and $\mathrm{WV}, 6.3-7.6 \mu \mathrm{m})$ of FengYun-2C (FY-2C), which is the first operational Chinese-based geostationary meteorological satellite. The spatial resolution of $\mathrm{FY}-2 \mathrm{C}$ is $5 \mathrm{~km}$ at the satellite nadir point, and it collects imageries hourly in normal state time and half hourly in rainy seasons. FY2C was launched successfully from Beijing on October 19, 2004.

At present, the satellite-based analysis of cloud usually uses Geostationary Operational Environmental Satellite (GOES) instruments (GOES-9-12 in particular), Advanced Very High Resolution Radiometer (AVHRR), Meteosat, and METEOSAT Second Generation (MSG). Studies from FengYun (FY) satellites are seldom found despite the fact that four operational geostationary meteorological satellites had been developed by China. Tracking and characterizing $\mathrm{Cb}$ from FY satellites may give new insight into the understanding of precipitation system of East Asia.

The main contribution of this paper can be summarized as follows: (1) presenting an automatic $\mathrm{Cb}$ tracking method based on the identification of $\mathrm{Cb}$ from cloud classification; (2) characterizing $\mathrm{Cb}$ systematically from geostationary satellite both from pixel and from cloud patch levels; and (3) improving the ability to track and investigate properties of $\mathrm{Cb}$ in East Asia using FY-2C and preparing cloud analysis and monitoring method for the upcoming launches of the FY-4 satellite series.

The structure of this paper is as follows. The proposed $\mathrm{Cb}$ detection and tracking method is presented in Section 2. Features of $\mathrm{Cb}$ identified by this method are introduced in Section 3. To illustrate the performance of this technique, specific cases are analyzed in Section 4 . The conclusions and discussion are given in Section 5.

\section{Methodology for Cb Tracking}

The objective of $\mathrm{Cb}$ tracking is to identify $\mathrm{Cb}$ from satellite imageries and to track their evolution on an image-by-image basis over time. In this work, the proposed technique of $\mathrm{Cb}$ tracking consists of three steps: the identification of $\mathrm{Cb}$ pixels using an artificial neural network (ANN) classifier [46], the detection of homogeneous $\mathrm{Cb}$ patches with a seeded region growing (SRG) algorithm, and the establishment of a relationship between current and previous $\mathrm{Cb}$ patches using a cross-correlation-based approach.

2.1. Cloud Classification. The purpose of this step is to extract various clouds from multichannel imageries using cloud classifiers.

Considering an ANN classifier as a biologically inspired computer program designed to simulate the way in which the human brain processes information, it is a promising modeling technique, especially for data sets having nonlinear relationships, which are frequently encountered in cloud classification processes. This study used an ANN cloud classification method for FY-2C data, which has been developed by comparing the capabilities of six widely used ANN methods (back 


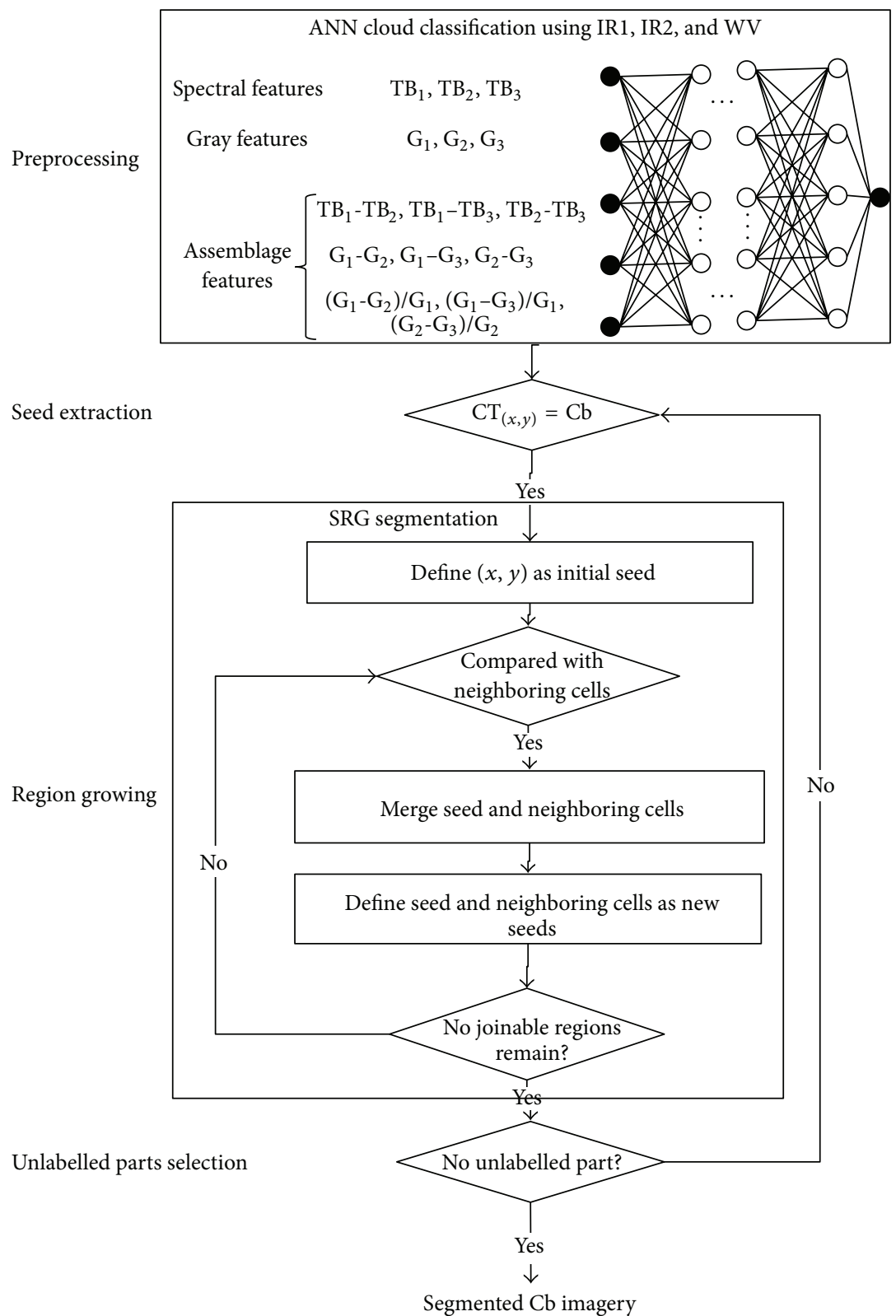

FIgURE 1: Configuration for cloud classification and segmentation of cumulonimbus (Cb). The cloud classification used artificial neural network (ANN) method, and segmentation used seeded region growing (SRG) method; $\mathrm{CT}_{\text {seed }}$ : cloud type of seed; $\mathrm{CT}_{(x, y)}$ : cloud type of pixel $(x, y) \cdot \mathrm{TB}_{1}, \mathrm{~TB}_{2}$, and $\mathrm{TB}_{3}$ are the brightness temperature (TB) of three infrared (IR) channels (IR1, 10.3-11.3 $\mu \mathrm{m}$; IR2, 11.5-12.5 $\mu \mathrm{m}$; and WV 6.3-7.6 $\mu \mathrm{m}$ ), respectively; $\mathrm{G}_{1}, \mathrm{G}_{2}$, and $\mathrm{G}_{3}$ are the gray value for three infrared (IR) channels, respectively.

propagation (BP), probabilistic neural network (PNN), modular neural networks (MNN), Jordan-Elman network, selforganizing map (SOM), coactive neurofuzzy inference system (CANFIS)), and two other methods (principal component analysis (PCA) and a support vector machine (SVM)). The scheme of the ANN cloud classification is shown in Figure 1. In this study, the ANN classifier divided cloud/ surface into seven categories: sea, stratocumulus and altocumulus, mixed cloud, altostratus and nimbostratus, cirrostratus, thick cirrus, and cumulonimbus using 2864 cloud samples manually collected by two experienced meteorologists in June, July, and August in 2007 from three FY-2C channels' (IR1, 10.3-11.3 $\mu \mathrm{m}$; IR2, 11.5-12.5 $\mu \mathrm{m}$; and WV 6.3$7.6 \mu \mathrm{m}$ ) imagery. And 15 features were chosen with numerous tests: 3 gray features $\left(G_{1}, G_{2}\right.$, and $\left.G_{3}\right), 3$ spectral features $\left(\mathrm{TB}_{1}, \mathrm{~TB}_{2}\right.$, and $\left.\mathrm{TB}_{3}\right)$, and 9 assemblage features $\left(\mathrm{G}_{1}-\mathrm{G}_{2}, \mathrm{G}_{1}-\right.$ $G_{3}, G_{2}-G_{3}, T_{1}-T_{2}, T_{1}-T_{3}, T_{2}-T_{3},\left(G_{1}-G_{2}\right) / G_{1},\left(G_{1}-\right.$ $\left.G_{3}\right) / G_{1}$, and $\left.\left(G_{2}-G_{3}\right) / G_{2}\right)$. The ANN classifier was composed of 2 hidden layers, and the neurons of the first and the second layer are 9 and 4, respectively. The learning step 
TABLE 1: Confusion matrix of the cloud classification using ANN classifier [46].

\begin{tabular}{|c|c|c|c|c|c|c|c|c|}
\hline Classes & Sea* & Land & Low-level clouds & Midlevel clouds & Thin cirrus & Thick cirrus & Multilayer clouds & $\mathrm{Cb}$ \\
\hline $\mathrm{Sea}^{* *}$ & 1.00 & 0.00 & 0.00 & 0.00 & 0.00 & 0.00 & 0.00 & 0.00 \\
\hline Land & 0.00 & 0.97 & 0.00 & 0.01 & 0.01 & 0.01 & 0.00 & 0.00 \\
\hline Low-level clouds & 0.04 & 0.05 & 87.00 & 0.02 & 0.02 & 0.00 & 0.00 & 0.00 \\
\hline Midlevel clouds & 0.01 & 0.00 & 0.02 & 0.92 & 0.05 & 0.00 & 0.00 & 0.00 \\
\hline Thin cirrus & 0.01 & 0.01 & 0.02 & 0.01 & 0.93 & 0.02 & 0.00 & 0.00 \\
\hline Thick cirrus & 0.00 & 0.00 & 0.00 & 0.01 & 0.02 & 0.92 & 0.05 & 0.00 \\
\hline Multilayer clouds & 0.00 & 0.00 & 0.00 & 0.03 & 0.00 & 0.01 & 0.90 & 0.06 \\
\hline $\mathrm{Cb}$ & 0.00 & 0.00 & 0.00 & 0.00 & 0.00 & 0.01 & 0.01 & 0.98 \\
\hline
\end{tabular}

Observed by experience; ${ }^{* *}$ classified by ANN.

and the learning momentums were set as 0.1 and 0.7 , and TanhAxon was used as a transfer function. More details concerning the classification method can be found in Liu et al. [46].

The accuracy results were shown in confusion matrix using 274 testing samples (Table 1). It can be seen that the cloud classifier can differentiate $\mathrm{Cb}$ well, and the possibility of misjudging other types of clouds as $\mathrm{Cb}$ was low with error rate below $6 \%$ [46].

This step reduces hundreds of pieces of satellite image data in float format to several pieces of cloud-type data in integer format. Each integer represents a special desired type of cloud patch $\left(\mathrm{CT}_{\text {desired }}\right)$.

2.2. Cloud Segmentation. The purpose of this step is to extract cloud boundaries and segment $\mathrm{Cb}$ patches using a seeded region growing (SRG) segmentation algorithm based on the result of previous ANN cloud classification. The ANN cloud classification can be thought of as a preprocessing procedure. SRG is an iterative process by which regions are merged starting from some initial segmentation-in this case, individual pixels - and then growing iteratively until every pixel has been processed. The scheme of the SRG segmentation is shown in Figure 1. It contains the following steps: (1) scan the image and identify $\mathrm{Cb}$ pixel that has not been labeled as a seed; (2) merge adjacent cloud cells to form a fragment if they are the same type as the seed and label each fragment as a completed region; (3) select unlabeled parts and reapply steps (1) and (2) until the entire image has been labeled.

As shown in Figure 1, unlike the traditional SRG method, this method is not sensitive to the rules for seed selection and growth. The reason is twofold: first, ANN cloud classifiers can reduce the number of infrared image values from hundreds of floats to several integers, where each integer represents a particular type of cloud; second, clouds identified by ANN always have a smoother boundary for the combination of multiple channels than do clouds identified with the traditional threshold methods.

2.3. $\mathrm{Cb}$ Tracking. The purposes of this step are to track $\mathrm{Cb}$ patches, to detect the different development stages of $\mathrm{Cb}$, and to provide an image sequence with indexed clouds. In general, the tracking method to detect cell patterns, whether radar- or satellite-data-based, can be divided into two main techniques: pattern-oriented correlation techniques and overlapping techniques [47]. This paper employs the former technique as well as the most common technique, a cross-correlation-based approach that uses two successive IR images to determine a displacement vector. In the first picture, digital image data of $3 \times 3$ pixels centered on the desired site are used as template data. In the second picture, taken one hour previously, image data of $15 \times 15$ pixels are used as search area data. The correlation coefficient of TB for the template area and the search area is calculated for each point to obtain a cross-correlation coefficient matrix, called a matching surface. The largest coefficient is adopted as the best-matched position at the pixel level, and the cloud advection was extracted. At the cloud patch level, if matched pixels make up more than $50 \%$ of the area of either the current cloud patch or the cloud patch from the previous time step, thus the patches are matched. Then, a cloud patch history log file is created to store tracking information and monitoring results.

The performance of the cloud tracking was evaluated with probability of detection (POD), false-alarm ratio (FAR), and critical success index (CSI). They are defined as follows:

$$
\begin{gathered}
\text { POD }=\frac{\text { hits }}{\text { hits }+ \text { misses }}, \\
\text { FAR }=\frac{\text { falsealarms }}{\text { hits }+ \text { falsealarms }}, \\
\text { CSI }=\frac{\text { hits }}{\text { hits }+ \text { misses }+ \text { falsealarms }},
\end{gathered}
$$

where hits, misses, and false alarms are the number of hits, failures, and false alarms of $\mathrm{Cb}$ pixels between the observed and the extrapolated imagery, respectively. The best tracking algorithm should be POD and CSI $=1, F A R=0$.

\section{Characterization of $\mathbf{C b}$}

In this study, $\mathrm{Cb}$ characteristics are derived at the pixel and patch levels, as shown in Table 2. Three types of cloud pixel parameters are extracted: coldness features, time series features, and situation features. Cloud patch features based on $\mathrm{Cb}$ tracking allow extraction of 19 features, which are composed of four types: coldness features, geometric features, 


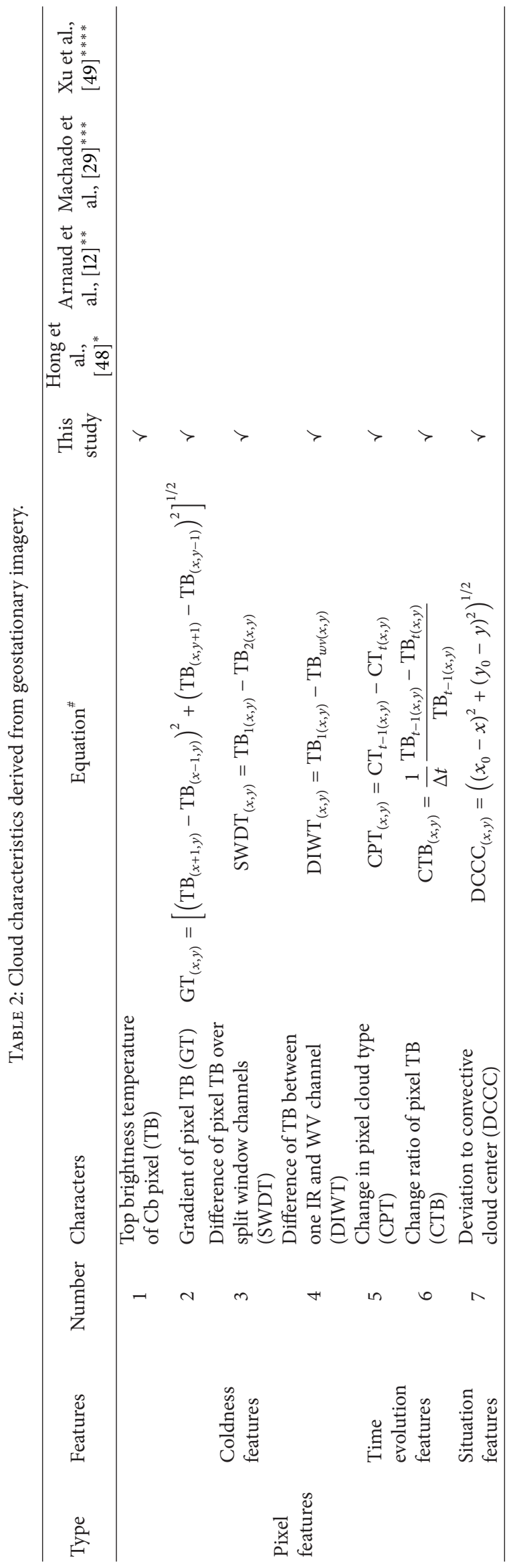




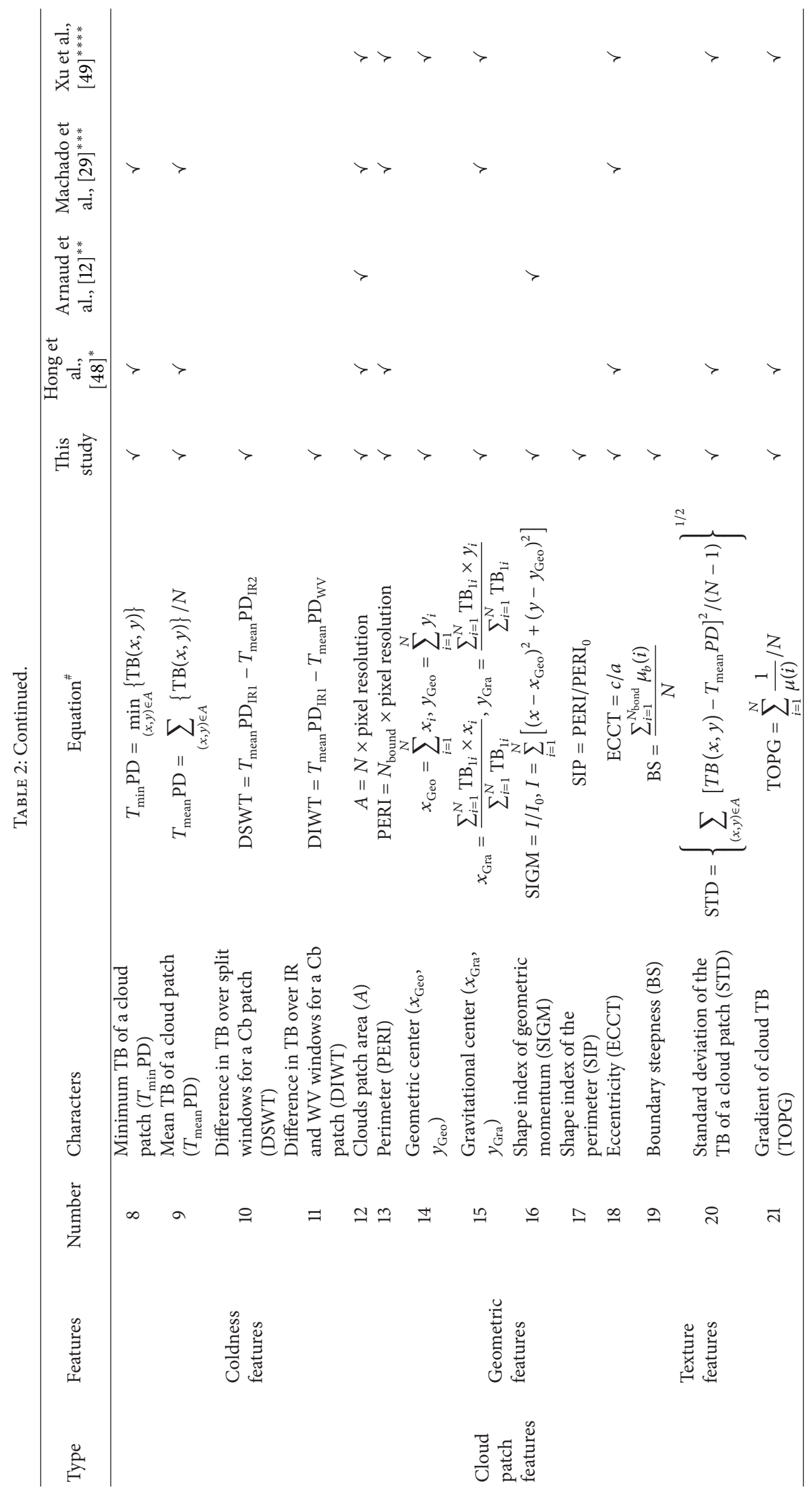




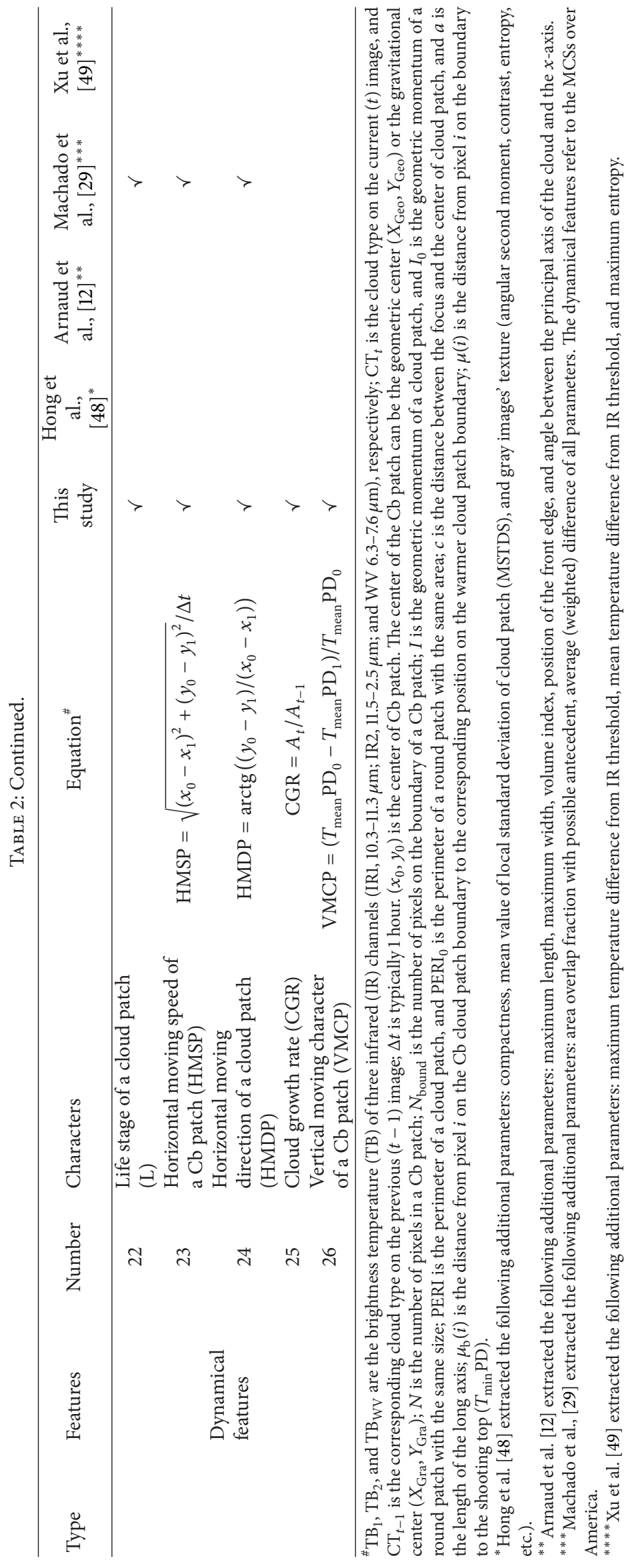


texture features, and cloud dynamic features. $\mathrm{Cb}$ dynamic features are composed of life stages and movement parameters. All cloud parameters obtained for each $\mathrm{Cb}$ patch are stored in a text file (.txt format), and some dynamical features are stored in an image file (.bmp format).

The cloud features can be described as follows.

3.1. Pixel Features. The height of cloud top by the brightness temperature (TB) and the convection strength by gradient of the TB (GT) are two parameters indicating cloud coldness feature. Three parameters of $\mathrm{TB}$ of three infrared channels $\left(\mathrm{TB}_{1}(10.3-11.3 \mu \mathrm{m}), \mathrm{TB}_{2}(11.5-12.5 \mu \mathrm{m})\right.$, and $\mathrm{TB}_{\mathrm{WV}}$ (6.3$7.6 \mu \mathrm{m})$ ) are used in this paper. GT is the gradient of $\mathrm{TB}$ for three infrared channels with a window size of $3 \times 3$ pixels, centered on pixel $i(x, y)$. Normally, clouds in the development stage correspond to a high cloud top, which can be indicated by less TB and more GT, and vice versa for clouds in the stable stage.

The difference of the TB (DT) can indicate the height and developmental character of convective clouds and is usually used to discriminate $\mathrm{Cb}$ and other underlying clouds. The DTs in this study are composed of two parameters: difference of pixel TB over split window channels (SWDT) and difference of TB between one IR and WV channel (DIWT). The former one is the difference in TB over split window channels (IR channels 1 and 2) and the latter one is the TB difference between IR channel 1 and the WV channel.

Change in pixel cloud type (CPT) and change in the ratio of pixel TB (CTB) are two parameters to show the time evolution features of $\mathrm{Cb}$ patch. $\mathrm{CPT}$ is the cloud type on the current image $\left(\mathrm{CT}_{t}\right)$ minus the corresponding cloud type on the previous image $\left(\mathrm{CT}_{t-1}\right)$, and it can indicate the conversion of cloud type. Six types of clouds (low-level clouds, midlevel clouds, thin cirrus, thick cirrus, multilayer clouds, and cumulonimbus) have been assigned values of 27 individually based on previous work of cloud classification [46]. CTB can be used to illustrate the cloud development on the vertical height for strong conviction corresponding to the cold cloud top.

The precipitation characters of $\mathrm{Cb}$ are always related to the deviation of the convective cloud center (DCCC). For example, heavy precipitation may occur not only in the convective center but also on the front of convective cloud patches. Thus, this study extracted two situation parameters, $\mathrm{DCCC}_{1}$ and $\mathrm{DCCC}_{2}$, according to the geometric center $\left(X_{\mathrm{Geo}}, Y_{\mathrm{Geo}}\right)$ and gravity center $\left(X_{\mathrm{Gra}}, Y_{\mathrm{Gra}}\right)$.

3.2. Cloud Patch Features. The coldness feature of cloud patch contains four parameters: minimum TB of a cloud patch $\left(T_{\text {min }} \mathrm{PD}\right)$, mean $\mathrm{TB}$ of a cloud patch $\left(T_{\text {mean }} \mathrm{PD}\right)$, difference in $\mathrm{TB}$ over split windows for a $\mathrm{Cb}$ patch (DSWT), and the difference in TB over IR and WV windows for a $\mathrm{Cb}$ patch (DIWT). Similar to the cloud on pixel level, rapid uplifting cloud patch has less $T_{\text {min }} \mathrm{PD}$ and $T_{\text {mean }} \mathrm{PD}$. DSWT and DIWT can indicate the developmental character of $\mathrm{Cb}$ with the information of cloud height and water vapor content.

The geometric feature of $\mathrm{Cb}$ clouds can be indicated by cloud patch area $(A)$, cloud patch perimeter (PERI), shape index of geometric momentum (SIGM), shape index of the perimeter (SIP), and eccentricity (ECCT). SIGM is the ratio of the geometric momentum of a cloud patch $I$ to that of a round patch with the same size $\left(I_{0}\right)$. SIP is the ratio of perimeter (PERI) of a cloud patch to that of a round patch with the same area $\left(\mathrm{PERI}_{0}\right)$. Normally, $\mathrm{Cb}$ in the early stage are always small and nearly round with low values for those geometric parameters compared to $\mathrm{Cb}$ in the developing and splitting stages, according to the observation.

The cloud texture/structure features on precipitation can be illustrated with three parameters: boundary steepness (BS), standard deviation of the TB of a cloud patch (STD), and gradient of cloud TB (TOPG). BS measures the temperature gradient along cloud patch boundary, and STD shows the standard deviation in a cloud patch. TOPG is the average temperature gradient from the overshooting top $\left(T_{\min } \mathrm{PD}\right)$ to each pixel on a $\mathrm{Cb}$ patch boundary.

Dynamic features of cloud can be indicated by 5 parameters, namely, life stage factor of the cloud patch (L), horizontal moving speed of the cloud patch (HMSP), horizontal moving direction of the cloud patch (HMDP), cloud growth rate (CGR), and the vertical moving character of the cloud patch (VMCP). HMSP is the displacement of the cloud patch centers between two successive images, while HMDP is a measure of the displacement of the cloud patch center. CGR is the ratio of the area of a current cloud patch $\left(A_{t}\right)$ to that of a previous one $\left(A_{t-1}\right)$. VMCP can be indicated by the ratio of the average $\mathrm{TB}$ of a current $\mathrm{Cb}$ patch $\left(T_{\text {mean }} \mathrm{PD}_{0}\right)$ to that of a previous one $\left(T_{\text {mean }} \mathrm{PD}_{1}\right)$, for cloud top TB reflects the height of $\mathrm{Cb}$. The life stages of $\mathrm{Cb}$ patches can be divided into 8 (Figure 2), which was also shown in Liu et al's previous work [50].

The technique for parameter estimation used in this study is similar to that used by Arnaud et al. [12] and Hong et al. [48]. Parameters such as the cloud patch growth rate (CGR) and the vertical moving character of a cloud patch (VMCP), as well as the introduction of $\mathrm{Cb}$ extraction based on cloud classification, are additions by this study. It should be noted that some cloud patch parameters, such as BS, STD, and TOPG, may not be very useful for early $\mathrm{Cb}$ clouds considering that some $\mathrm{Cb}$ in the initial stage are always on a scale of $\sim 1-2$ pixels.

\section{Results}

Because of the great spatial and temporal variation in cloud type, location, shape, and height, it is hard to use other satellites as a reference comparison for different scanning areas of geostationary satellites and limited frequency of polar-orbiting satellites, not to mention that there are no mature satellite-based $\mathrm{Cb}$ tracking products. Similarly, it is also not proper to use radar data for comparison because of their limited coverage area, while geostationary satellites observe clouds globally. Therefore, to evaluate the proposed $\mathrm{Cb}$ detection and tracking method, the tracking results of 8 cases are compared with their respective cloud classification maps. Another method of assessment is to examine the temporal evolution of the cloud parameters for continuous 


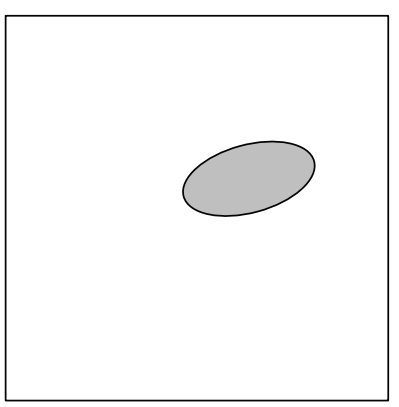

(a)

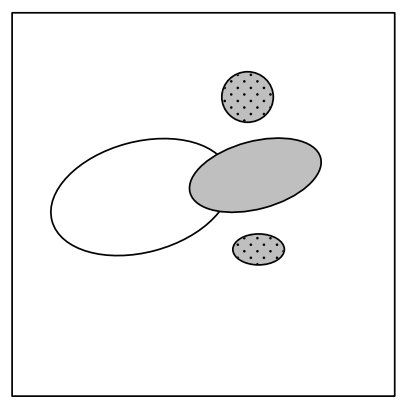

Cloud patch

in the current image

Other cloud patches

in the current image

Cloud patch in the

previous time step image

$\odot \begin{aligned} & \text { Other cloud patches in the } \\ & \text { previous time step image }\end{aligned}$

(e)

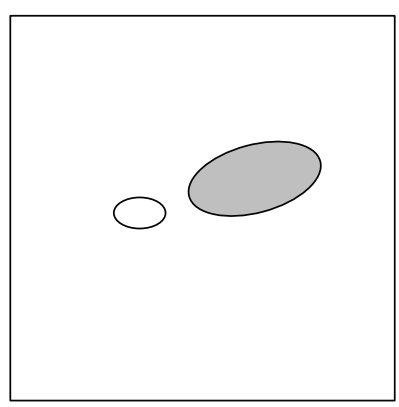

(b)

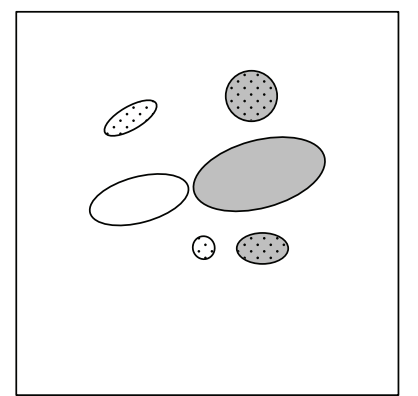

$\bigcirc$ Cloud patch

in the current image

Other cloud patches

in the current image

Cloud patch in the

previous time step image

$\odot \begin{aligned} & \text { Other cloud patches in the } \\ & \text { previous time step image }\end{aligned}$

(f)

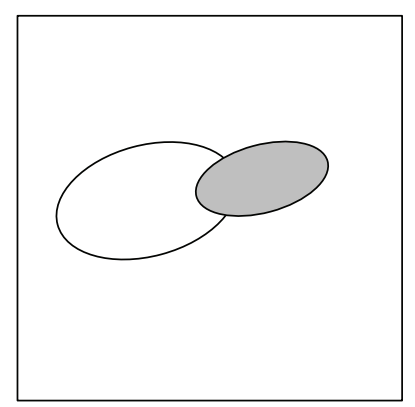

(c)

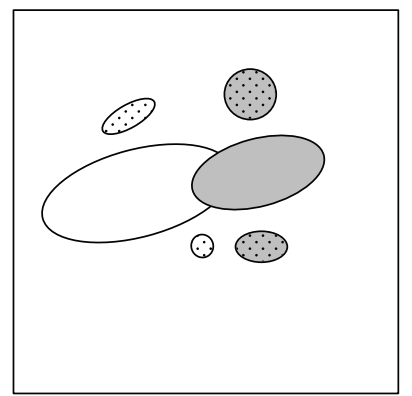

Cloud patch

in the current image

Other cloud patches

in the current image

Cloud patch in the

previous time step image $\odot \begin{aligned} & \text { Other cloud patches in the } \\ & \text { previous time step image }\end{aligned}$

(g)

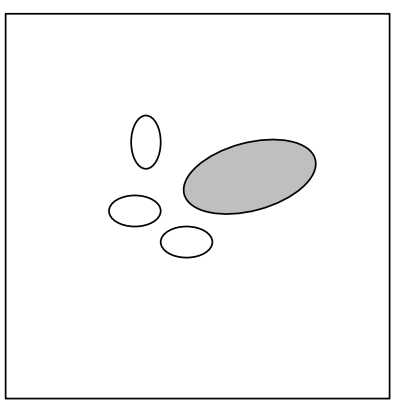

(d)

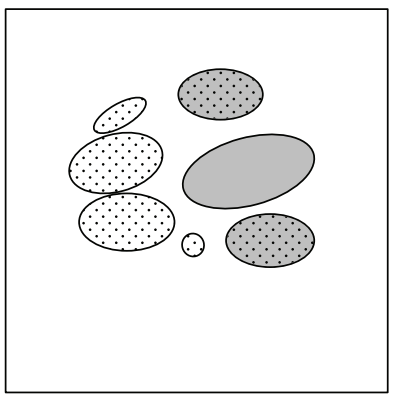

Cloud patch

in the current image

Other cloud patches

in the current image

Cloud patch in the

previous time step image

$\odot \begin{aligned} & \text { Other cloud patches in the } \\ & \text { previous time step image }\end{aligned}$

(h)

Figure 2: Diagram of the life stages of a cloud patch (L). (a)-(c) demonstrate birth and straightforward continuations for a single cloud patch; (d)-(h) show complicated Cb patches with other minor splits, mergers concerned. (a) The birth of a new Cb patch (L1). There is no previous corresponding $\mathrm{Cb}$ patch for the current $\mathrm{Cb}$ patch; (b) development of single cloud patch (L2). It is characterized with straightforward continuation of a $\mathrm{Cb}$ patch with area increasing; (c) dissipation of single cloud patch (L3). It is the same as L2 but with area decreasing; (d) merge of complex cloud patch (L4). A Cb patch is a few $\mathrm{Cb}$ patches merger; (e) dissipation into several Cb patches (L5). A Cb patch breaks up into several $\mathrm{Cb}$ patches; (f) development of complex $\mathrm{Cb}$ patch (L6); a $\mathrm{Cb}$ patch simultaneously breaks up and absorbs another preexisting cloud while absorption takes the main trend; (g) dissipation of complex cloud patch (L7). Similar to (f) while the dissipation takes the main trend; (h) uncertain cloud patch (L8). Similar to (f) while there is no obvious dissipation process.

evolution indicating consistent tracking. This also allows, for example, the evaluation of the cloud development characteristics by cross-comparison of different parameters.

In Section 4.1, the results of the cloud classification and segmentation of $\mathrm{Cb}$ are presented. In Section 4.2, cloud tracking results and some dynamic parameters are shown. The time evolution of $\mathrm{Cb}$ patch parameters for one case is given in Section 4.3.

4.1. Results of Cloud Classification and Segmentation. Figure 3 displays an application of the proposed algorithms to a $\mathrm{Cb}$ event at 03:00 UTC on July 4, 2007. Figures 3(a)-3(b) show two FY-2C cloud imageries at consecutive time steps. Figure 3(c) is the result of the cloud classification which indicates that convective storms were rapidly developing throughout the tropics and midlatitudes at 03:00 UTC on July 4. According to the previous cloud classification validation test [46], the ANN model can detect $\mathrm{Cb}$ with approximately $90.74 \%$ accuracy (Table 1), compared to $76.49 \%$ for the FY-2C operational product. The cloud classification results obtained thus far have been encouraging.

Figure 3(d) shows $\mathrm{Cb}$ patches segmented from cloud classification imagery, and the varying color indicated different life stages, which is analyzed later in this paper. To further understand the proposed SRG method, this study compared it to a traditional TB threshold-based SRG method with a MCCs case (Figure 4). Reasons for limiting to the MCCs case lie in the fact that there exists a definite TB threshold of $-52^{\circ} \mathrm{C}$ for MCCs according to its definition [51] while there is no acknowledged TB threshold for other clouds, such as MCSs. The results show that the proposed SRG method can provide differentiating $\mathrm{Cb}$ well from multilayer clouds compared to the TB threshold-based method.

The above results show that the detection of homogeneous $\mathrm{Cb}$ clusters, the first objective in $\mathrm{Cb}$ tracking, can be 


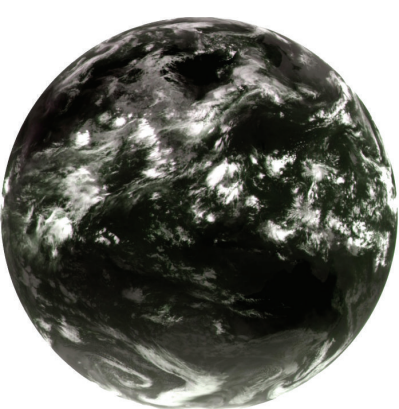

(a)

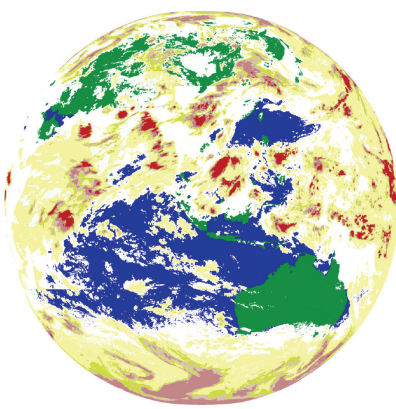

(c)

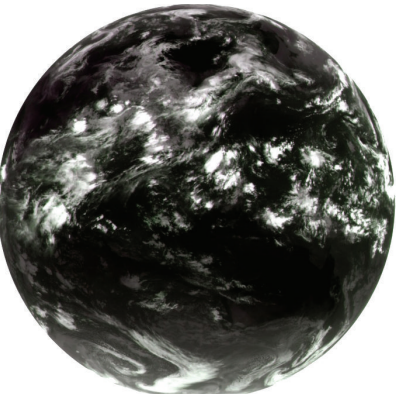

(b)
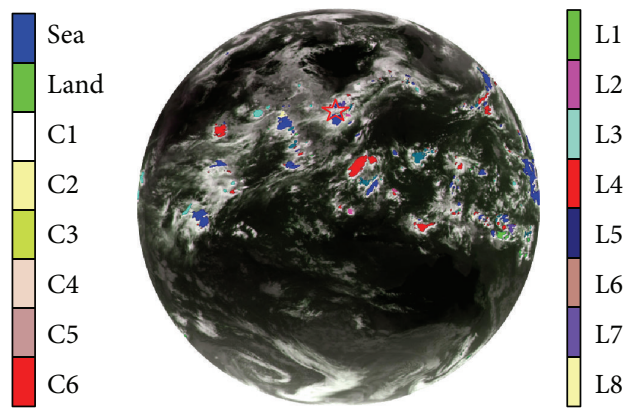

(d)

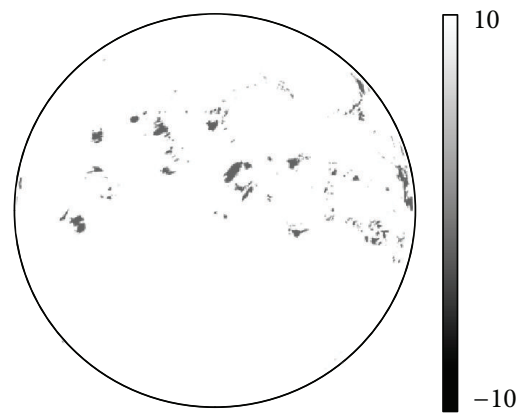

(e)

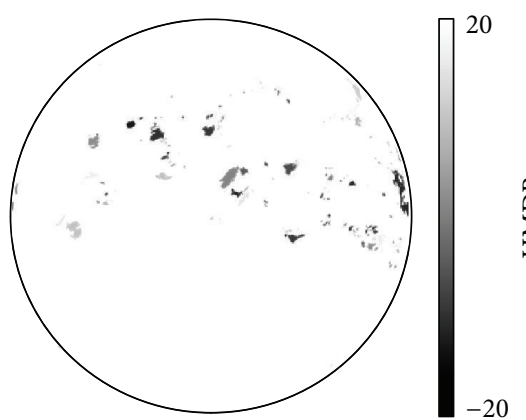

(g)

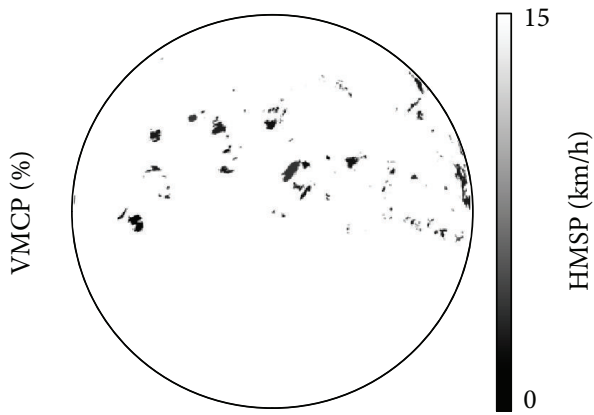

(f)

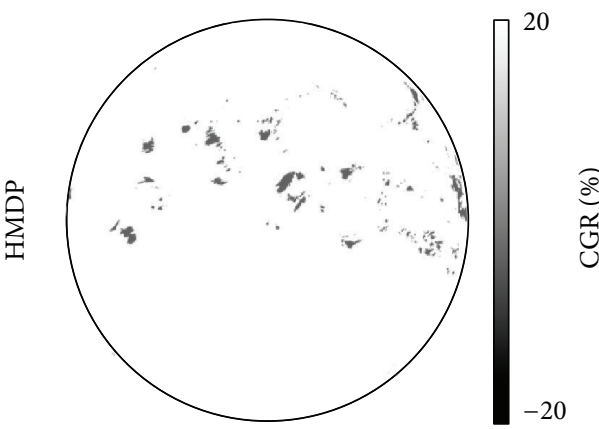

(h)

FIGURE 3: Result of the Cb tracking and dynamical parameters of cloud patch at 03:00 UTC on July 4, 2007. (a) Synthesis map of IR1, IR2, and WV at 02:00 UTC of July 4, 2007. (b) The same as (a) but for 03:00 UTC July 4, 2007; (c) cloud classification results (C1: stratocumulus and altocumulus; C2: altostratus and nimbostratus; C3: mixed cloud; C4: cirrostratus; C5: thick cirrus; C6: cumulonimbus); (d) life stages (L) of Cb. L1, L2 ․ L8 means the same as in Figure 2. Red star shows a Cb patch with gravitational center $\left(27.52^{\circ} \mathrm{N}, 103.85^{\circ} \mathrm{E}\right)$; (e) vertical moving character of $\mathrm{Cb}$ patches (VMCP); (f) horizontal moving speed of cloud patches (HMSP); (g) horizontal moving direction of cloud patches (HMDP); (h) cloud growth rate (CGR). 


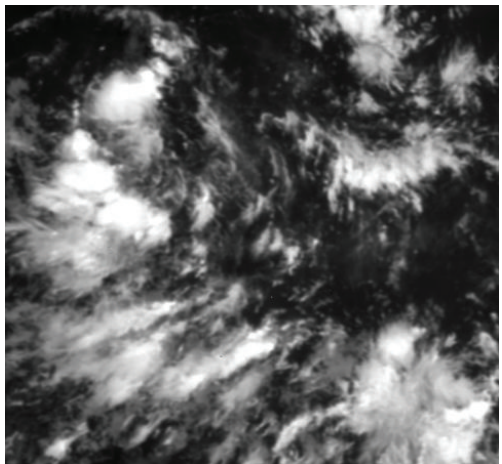

(a)

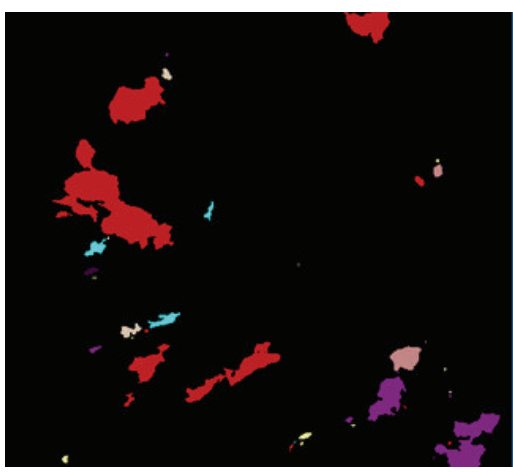

(c)

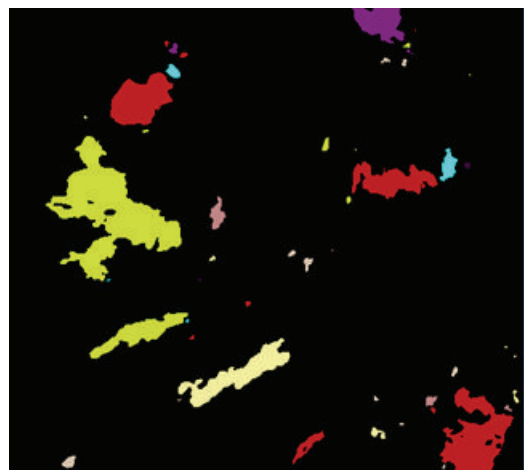

(b)

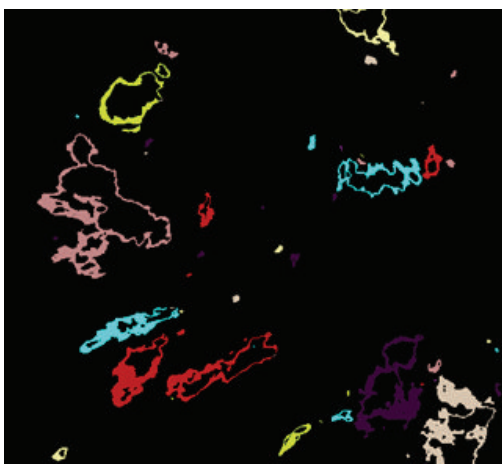

(d)

FIGURE 4: Segmentation result of the Cb and mesoscale convective complexes (MCCs) (03:00 UTC on July 3, 2008). (a) IR1; (b) segmented MCCs using $-52^{\circ} \mathrm{C}$ as TB threshold; (c) segmented $\mathrm{Cb}$ using the proposed SRG method with ANN classification as preprocess; (d) the same as (c) but for segmented multilayer cloud. The color of cloud patches in (b), (c), and (d) is generated randomly.

achieved by combining ANN cloud classification and SRG segmentation. The main reason lies in the fact that SRG method is not sensitive to the TB threshold as the traditional SRG method is, for the preprocess of ANN cloud classifiers reduces hundreds of pieces of float data in satellite imagery data to several pieces of integer data.

4.2. Cloud Tracking and Characterization. Figure 5 is the POD, FAR, and CSI of cloud tracking results of 30 FY-2C imageries (05:00 UTC on 5 July to 10:00 UTC on 4 July). It shows that the average POD, FAR, and CSI of the $\mathrm{Cb}$ are $67.18 \%, 15.38 \%$, and $59.88 \%$.

Figures $3(\mathrm{~d})-3(\mathrm{~h})$ show five $\mathrm{Cb}$ dynamic parameters (L, HMSP, HMDP, CGR, and VMCP). The main reason for limiting the number of parameters to 5 is that other parameters used in this study are similar to those used by Arnaud et al. [12], although there are some differences in their definitions. These 5 parameters, along with the extraction of $\mathrm{Cb}$ based on cloud classification, are the contributions of this study to the presently used scheme. In addition, they can be used as a prediction index for hurricane because of their close relationship to the potential of heavy rainfall. Figures 3(d)$3(\mathrm{~h})$ show that the life stages and moving characteristics of $\mathrm{Cb}$ patches vary greatly. Taking the cloud stage factor $\mathrm{L}$ as example, it can be seen that the life stages L1 (the birth of a new cloud patch), L2 (development of a single cloud patch),

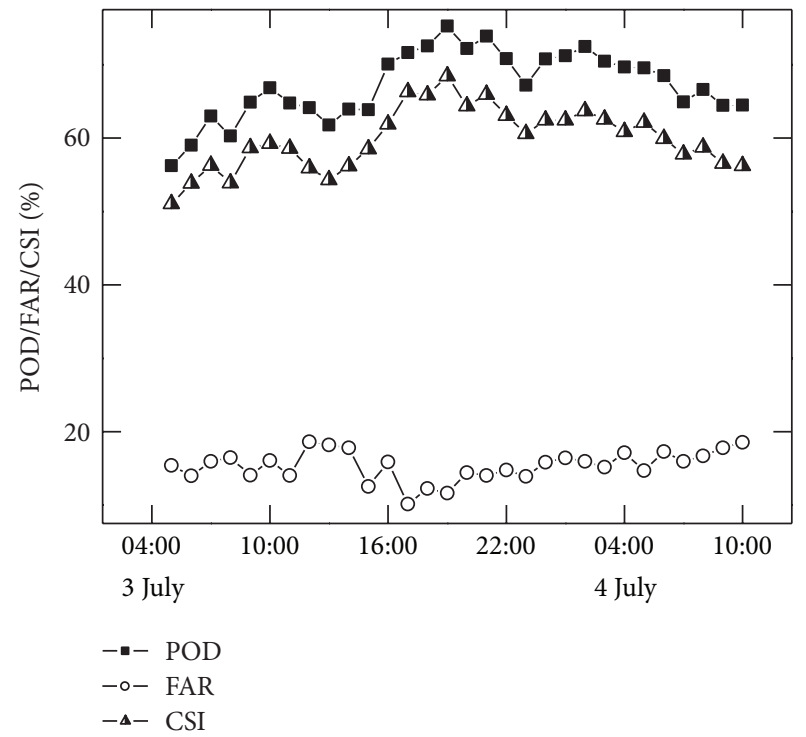

FIGURE 5: POD, FAR, and CSI of the $\mathrm{Cb}$ tracking algorithm for 30 imageries (05:00 UTC on 5 July to 10:00 UTC on 4 July).

and L4 (merging of complicated cloud patches) are the most common in this case. Occurrences of L7 (development of complicated $\mathrm{Cb}$ patches) and L8 (uncertain cloud patches) are 
relatively rare and are often found in a series of $\mathrm{Cb}$ patches that developed in large-scale events such as hurricanes. According to some statistical analyses, the cloud life stages are closely related to $\mathrm{Cb}$ rainfall intensity and probability, and the relationship can be used in precipitation estimation [51].

For demonstration purposes, 8 cases of $\mathrm{Cb}$ showing

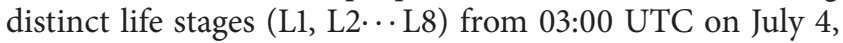
2007 , are used to assess the performance of the proposed method (Figures 6(a)-6(h)). Figures 6(a)-6(c) show cases of $\mathrm{Cb}$ patches that develop simply, while Figures 6(d)-6(g) show cases with minor $\mathrm{Cb}$ splits and mergers. Figure 6(h) shows a case of uncertain life stage for there are many simultaneous major splits and mergers.

As shown in Figures 6(a1)-6(a3), the Cb patch marked with black cross (Figure 6(a3)) is a newborn patch that was only a weak convective initiation system in previous maps (Figure 6(al)). Figures 6(b)-6(c) show that the $\mathrm{Cb}$ patches located in the center of the picture developed or dissipated simply, while Figures 6(d)-6(g) display similar developmental characteristics as Figures 6(b)-6(c), except with a few minor splits and mergers. Figure 6(h) shows a case whose development and dissipation are uncertain for there are many mergers and splits of similar intensities. These results show that the configuration and development stages of $\mathrm{Cb}$ identified by the algorithm are close to reality.

4.3. Time Evolution of Various Parameters. The temporal evolution of a Cb case on July 3-4, 2007, in southwest China $\left(27.5^{\circ}-29.5^{\circ} \mathrm{N}, 99^{\circ}-103^{\circ} \mathrm{W}\right)$ was analyzed to demonstrate the proposed cloud tracking method. The location of it at 03:00 UTC on 4 July was marked by a red star in Figure 3(d).

(1) Temporal Evolution of Coldness Features. The $T_{\text {mean }} \mathrm{PD}$ and $T_{\min }$ PD of the Cb patch show similar variations (Figure 7(a)): both decrease after 05:00 UTC on 3 July and reach their minima at approximately 11:00 UTC. The temperatures then fluctuate while generally rising until 02:00 UTC on 4 July. The values of SWDT and DIWT are negative and have similar peak times to those of $T_{\text {mean }} \mathrm{PD}$ (Figure 7(b)).

\section{(2) Temporal Evolution of Geometric Features}

(i) Area and Perimeter. Figure 7(c) shows that there was a continuous increase in cloud area until 08:00 UTC on 3 July. After that, the cloud area continued to increase rapidly from 08:00 to 10:00 UTC with some $\mathrm{Cb}$ mergers. In the next stage, at 14:00 UTC, the cloud cell dissipated. Then, three similar life cycles occurred between 14:00 UTC and 09:00 UTC the next day, when the cloud cell disappeared. During these life cycles, this $\mathrm{Cb}$ cell experienced many minor splits and mergers that were identified by the proposed method.

(ii) Displacement of the Geometric and Gravitational Centers of the $\mathrm{Cb}$ Patch. Representing the simultaneous evolution of the center position of the $\mathrm{Cb}$ patch is useful because cloud development can be related to geographical characteristics. Figure $7(d)$ shows the analysis of the system trajectory. It shows that, in most cases, the system propagates from northwest to southeast. On the whole, the geometric centers are consistent with the gravitational centers, but more smoothness and continuity can be seen in the displacement of gravitational centers of small cloud patches. This finding indicates that the initial stages of $\mathrm{Cb}$ patches are always associated with irregular and rapidly changing shapes. Discontinuities that occurred at four sites (with gravitational centers $29.5^{\circ} \mathrm{N}, 99.2^{\circ} \mathrm{W} ; 28^{\circ} \mathrm{N}, 100.5^{\circ} \mathrm{W} ; 27.5^{\circ} \mathrm{N}, 102^{\circ} \mathrm{W}$; and $27.5^{\circ} \mathrm{N}, 103^{\circ} \mathrm{W}$ ) were due to the merger of some minor $\mathrm{Cb}$ patches previously located ahead of the perturbation.

(iii) Shape Character. Figure 7(e) shows that the SIGM experienced successive increases and decreases between 06:00 UTC on 3 July and 01:00 UTC on 4 July corresponding to the modulations of the SIP. The variation is the opposite for the other two periods, 05:00-0600 UTC on 3 July and 01:00-09:00 UTC on 4 July, which is related to the birth of a small $\mathrm{Cb}$ patch and the dissipation of a few complicated $\mathrm{Cb}$ patches. ECCT varied from 0.9 to 1.0 and experienced similar variations to those experienced by SIP and SIGM.

(3) Temporal Evolution of Texture Features. Figure 7(f) shows that the TOPG increased from 05:00 UTC on 3 July reached its peak at 11:00 UTC, and then decreased until 18:00 UTC on 4 July. Another increase and decrease took place thereafter. The peaks appear to correspond to the shape parameters, SIP, and the merging and dissipation of other minor $\mathrm{Cb}$ cells. The other two textural features, STD and BS, show a continuous similar variation TOPG. Overall, the major peak of STD occurred first, followed by peaks of BS and TOPG. BS always peaked approximately one hour ahead of TOPG, which may be an important indication for precipitation prediction.

(4) Temporal Evolution of Cloud Dynamical Features

(i) Cloud life stage: Figure $7(\mathrm{~g})$ shows that the $\mathrm{Cb}$ patch was born at 05:00 UTC on July 3, 2007. It grew simply (L2) and developed rapidly by merging with other $\mathrm{Cb}$ cells (L4 and L6) before 00:00 UTC on 4 July. Thereafter, it decreased in size and disappeared at 09:00 UTC on 4 July.

(ii) Motion character: Figures $7(\mathrm{~h})-7(\mathrm{i})$ show that the value of CGR evolved with the change of life stage: CGR was positive for developing $\mathrm{Cb}$ stages (L2, L4, and L6) and was negative for dissipating $\mathrm{Cb}$ stages (L3, L5, and L7). The major peak of horizontal moving directions (HMDP) occurred at the moment of merging and dissipation of other minor cloud patches. The horizontal moving character (HMSP) showed similar variations to the vertical moving character (VMCP). Generally, a greater absolute value of VMCP is associated with greater HMSP, which indicates stronger convective systems that produce heavyrainfall. 


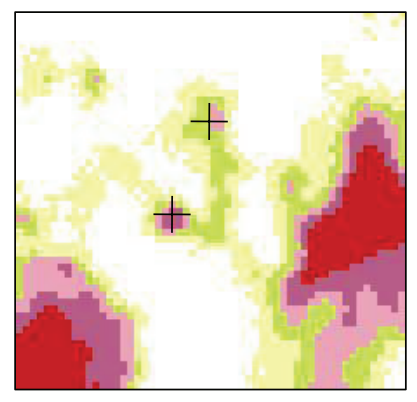

(a1)

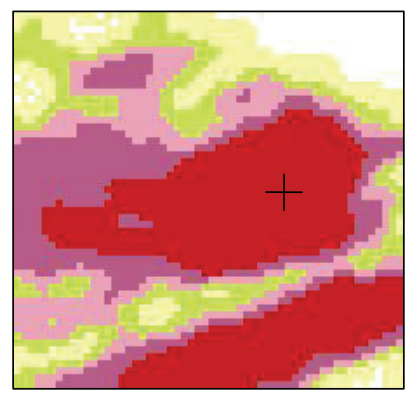

(b1)

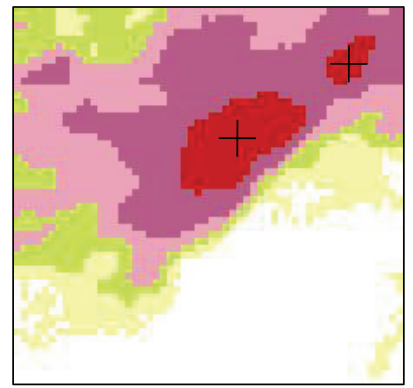

(c1)

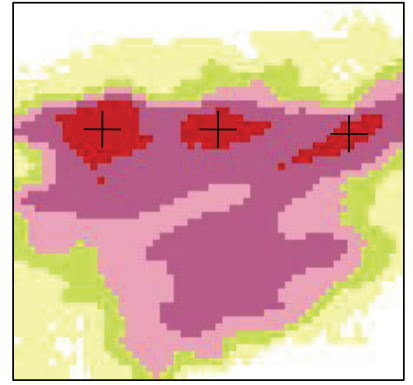

(d1)

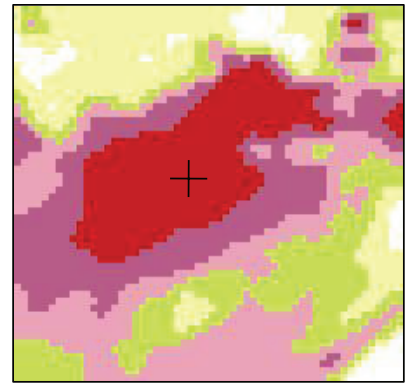

(e1)

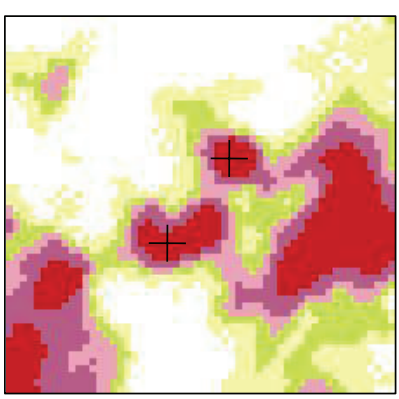

(a2)

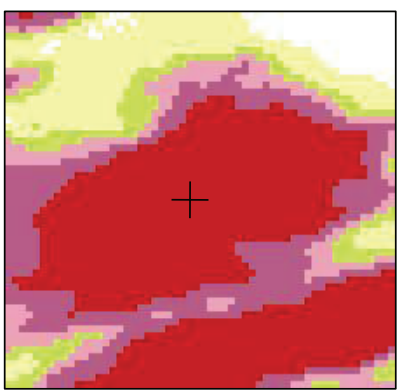

(b2)

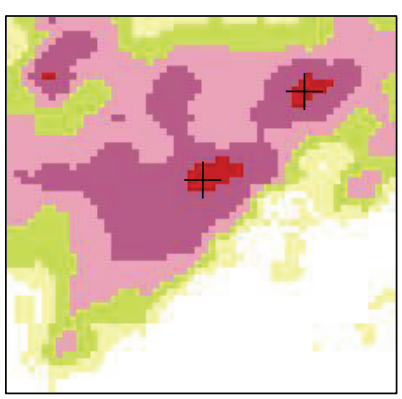

(c2)

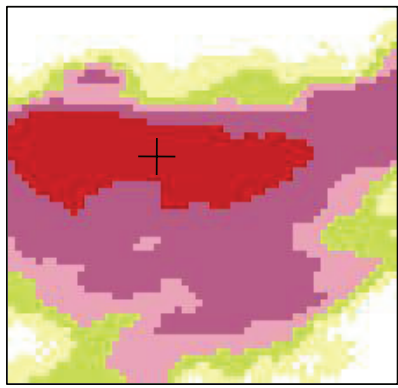

(d2)

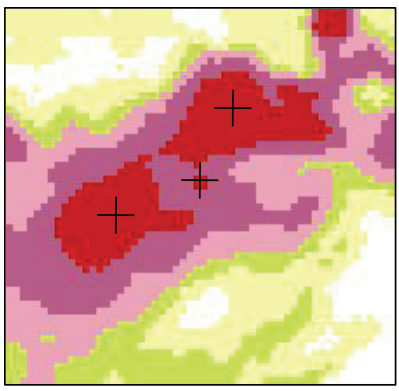

(e2)

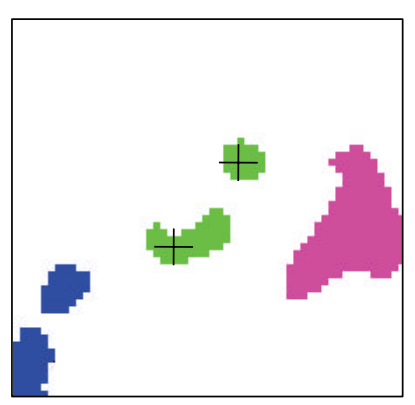

(a3)

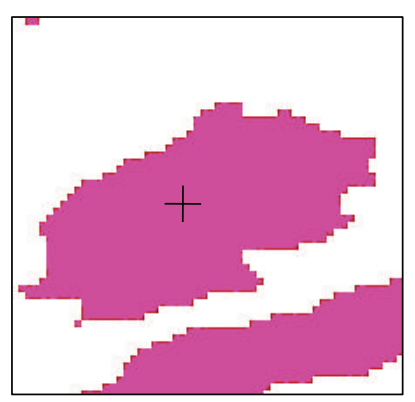

(b3)

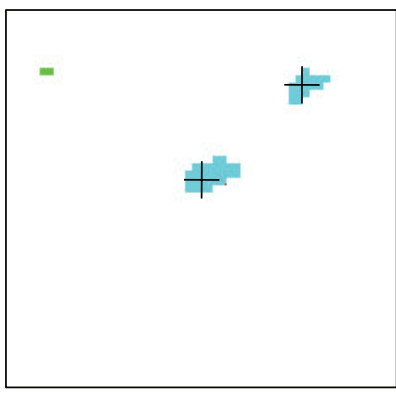

(c3)

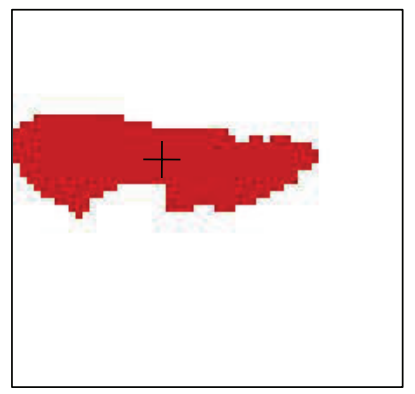

(d3)

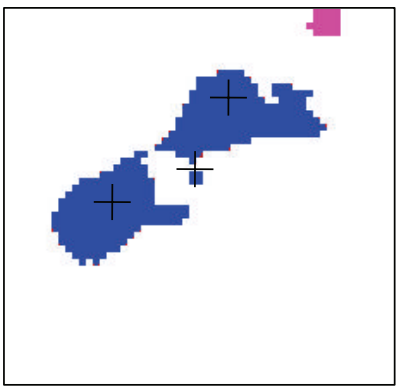

(e3)

FIGURE 6: Continued. 


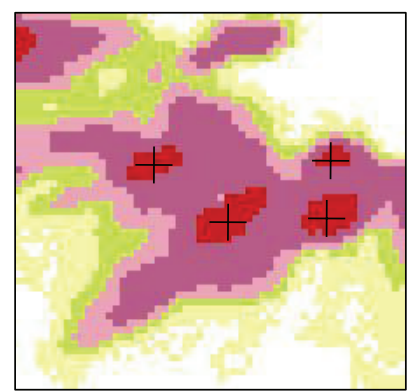

(f1)

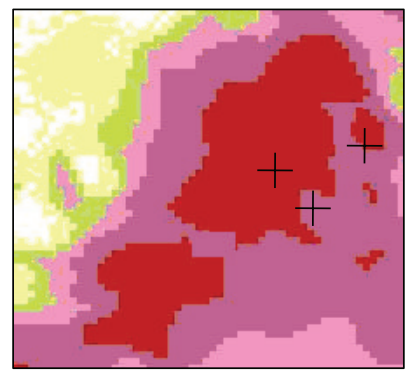

(g1)

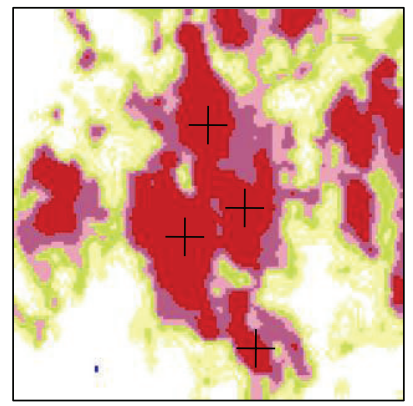

(h1)

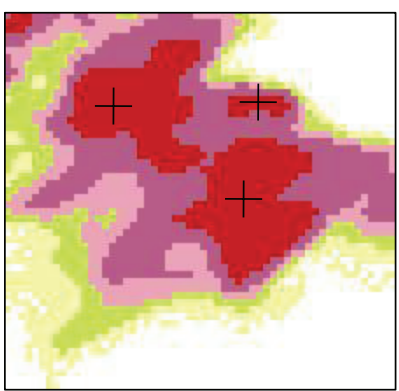

(f2)

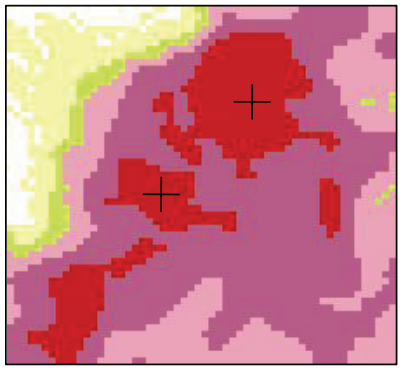

(g2)

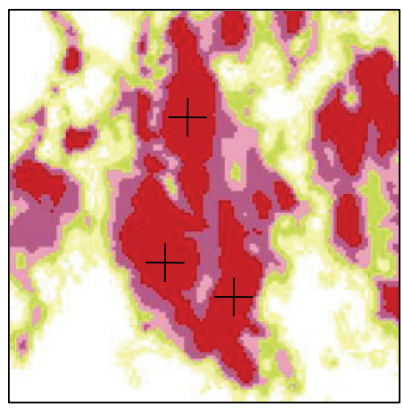

(h2)

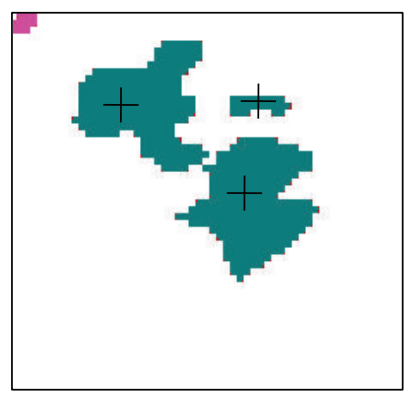

(f3)

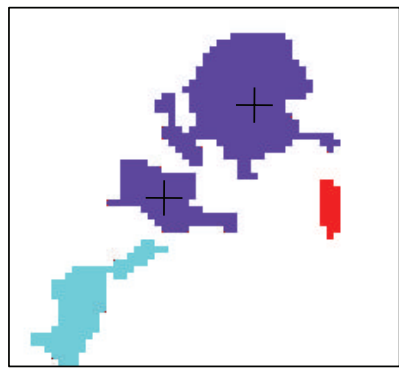

(g3)

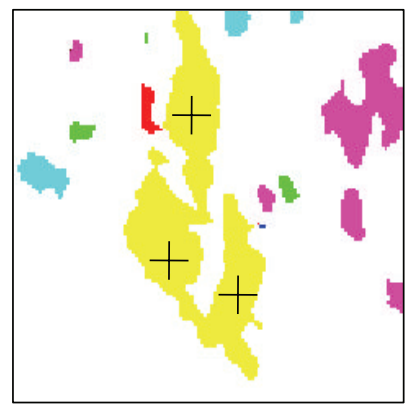

(h3)

FIGURE 6: $\mathrm{Cb}$ patches in various life stages. The analyzed $\mathrm{Cb}$ patches are always located in the center of picture and their gravitational centers are marked with black criss-cross. The first column (a1, b1 $\cdots$ h1) is the classification results at 02:00 UTC of July 4, 2007; the second column $(\mathrm{a} 2, \mathrm{~b} 2 \cdots \mathrm{h} 2)$ is the same as the first column but for 03:00 UTC; the third column (a3, b3 $\cdots \mathrm{h} 3)$ is the determination of life stages, respectively (a3: L1; b3: L2; c3: L3; d3: L4; e3: L5; f3: L6; g3: L7; h3: L8). L1, L2 ․ L8 means the same as that of Figure 2.

\section{Conclusion and Discussion}

This study proposed a new approach to track $\mathrm{Cb}$ from FY-2C images, which consists of three stages: identifying $\mathrm{Cb}$ pixels based on ANN cloud classification, segmenting $\mathrm{Cb}$ patches with a seeded region growing algorithm (SRG), and tracking $\mathrm{Cb}$ patches using a cross-correlation-based approach. Then, 27 cloud parameters ( 7 pixel parameters and 20 cloud patch parameters) were extracted to characterize $\mathrm{Cb}$ behavior at the pixel and patch levels. The performance of the $\mathrm{Cb}$ detection and tracking method was demonstrated with 8 cases of distinct life stages and the time evolution of $\mathrm{Cb}$ patch parameters for one case.

The result shows the following.

(1) The cloud classification based Cb tracking method reduces the uncertainty in $\mathrm{Cb}$ identification for it is not sensitive to the TB thresholds which are widely used in the traditional SRG method.

(2) The proposed method is not only capable of locating and tracking $\mathrm{Cb}$ until dissipation, but is also capable of dealing with more complicated systems related to moving disturbances.

(3) Analysis of the evolution of $\mathrm{Cb}$ patch parameters demonstrates some interesting results, such as a direct correspondence among cloud coldness features, geometric features, texture features, and dynamic features. Characterizing $\mathrm{Cb}$ from geostationary satellite and analysis can provide deep insight into the precipitation estimation and nowcasting.

Because this is the initial part of the current research that is more focused on the methodology, more complex and advanced scenarios (e.g., individual cloud patches) still need to be investigated and comprehensively evaluated. In 


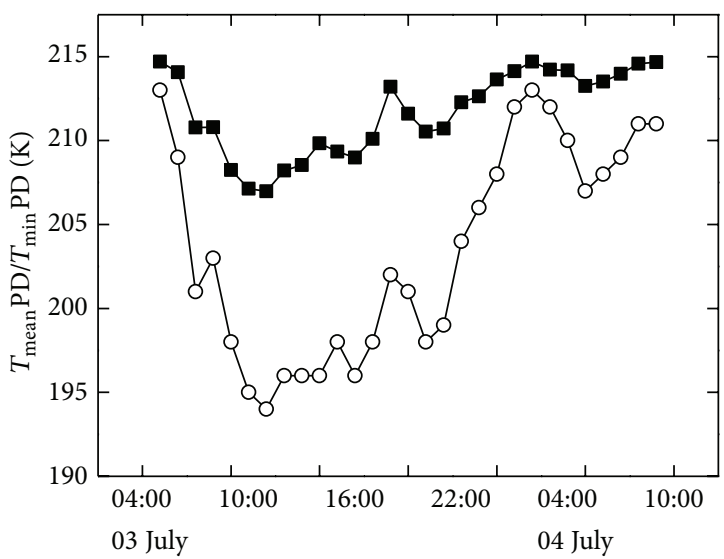

Time (UTC)

$\rightarrow$ TmeanPD

- - TminPD

(a)

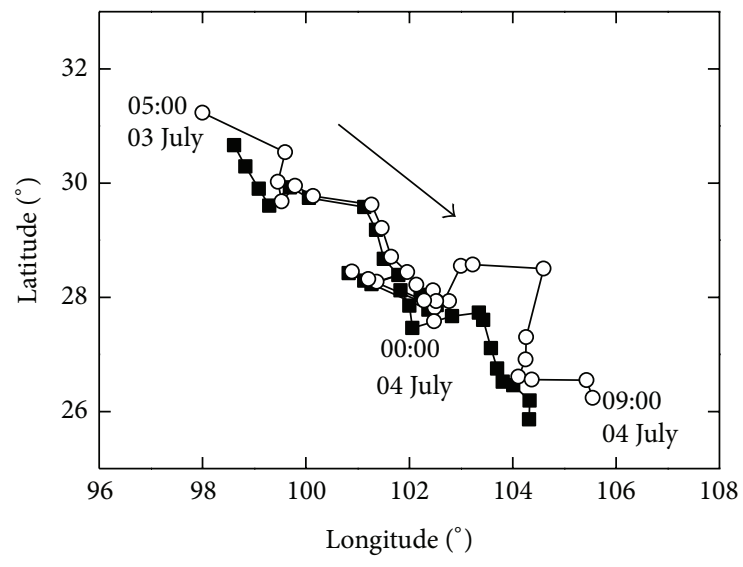

- Gravity center

-o- Geometric center

(c)

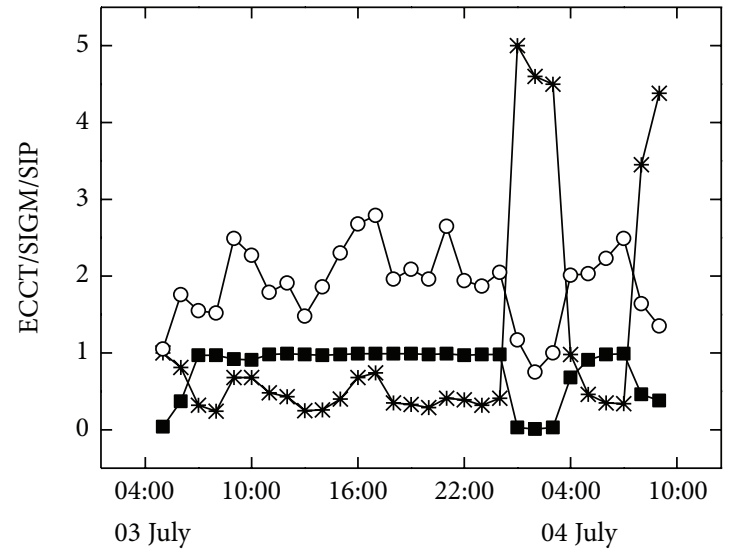

Time (UTC)

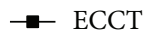

$\rightarrow$ SIGM

$-\circ$ SIP

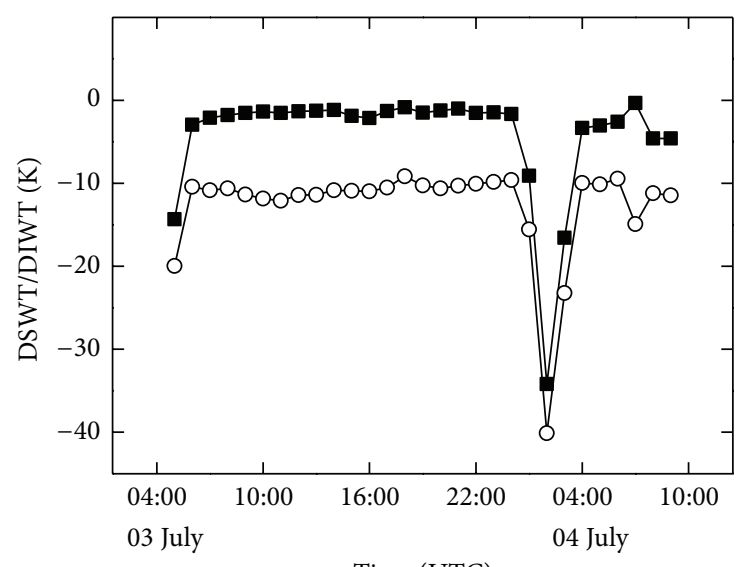

Time (UTC)

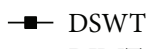

-0 DIWT

(b)

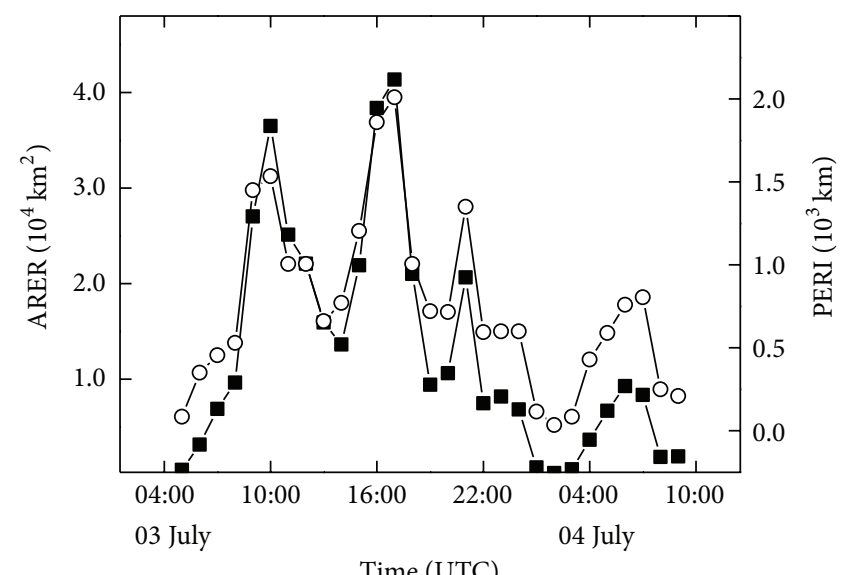

-m- AREA

-O- PERI

(d)

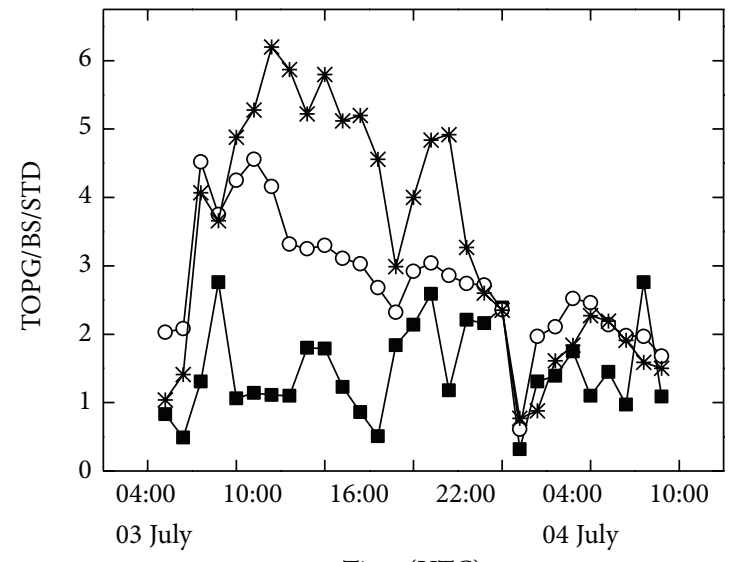

Time (UTC)

$\rightarrow$ TOPG

$-\infty$ BS

* STD

(e) 

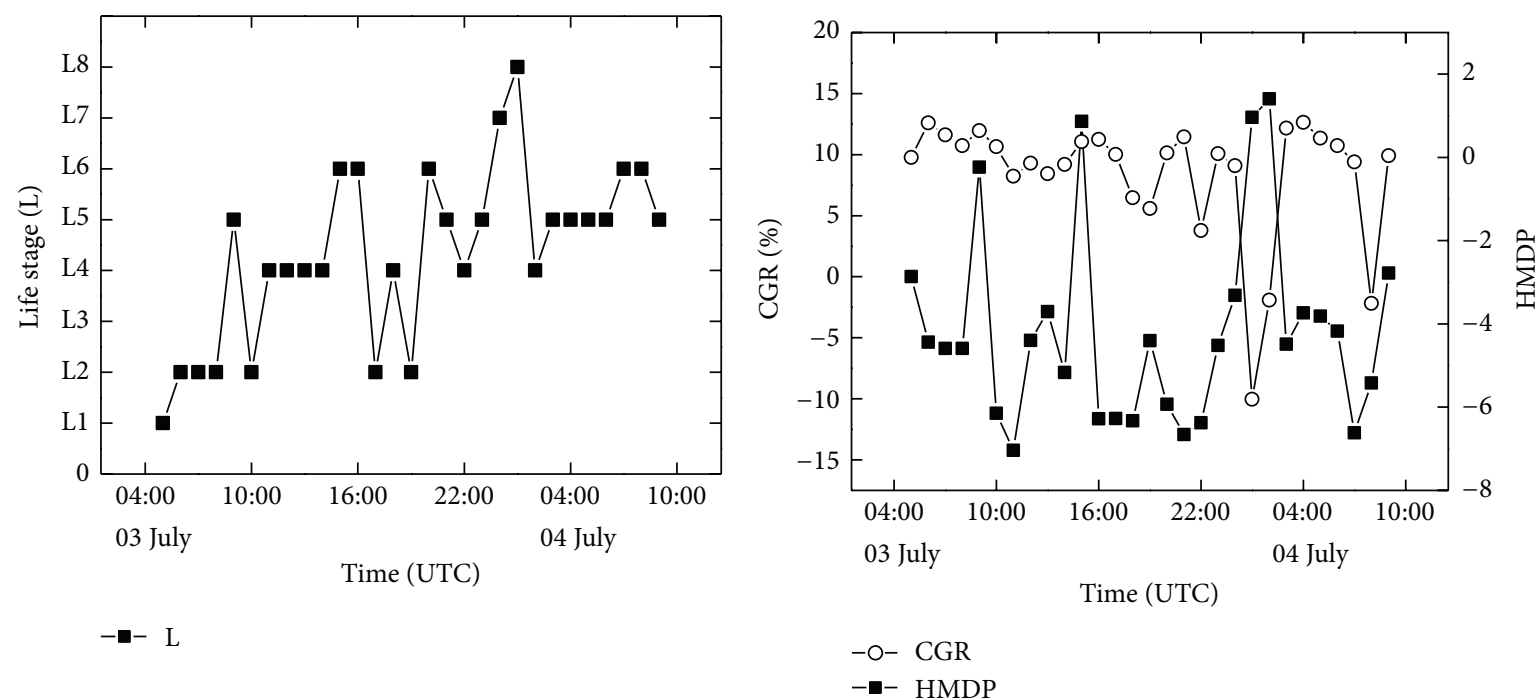

(g)

(h)

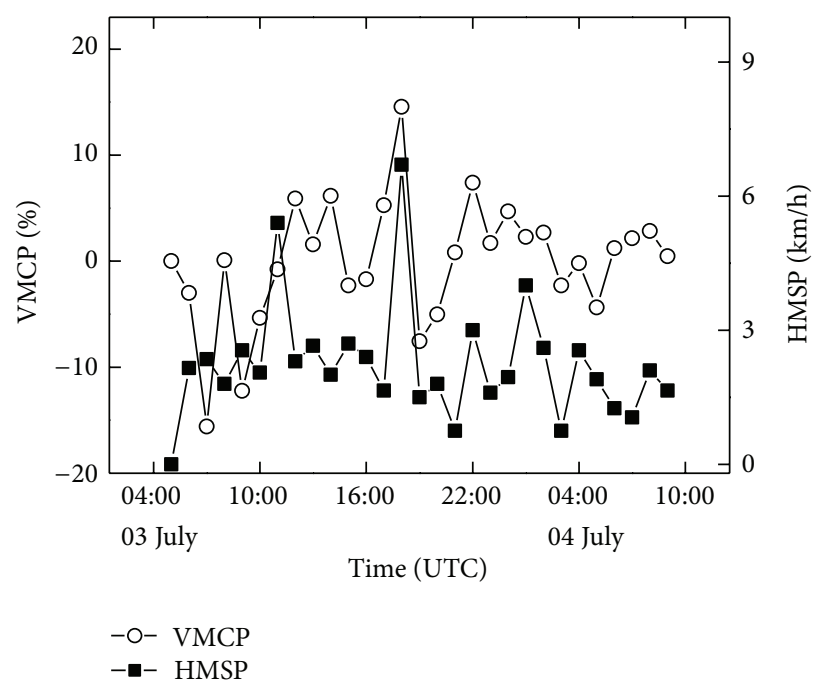

(i)

FIgURE 7: Temporal evolution of cloud patch features for a $\mathrm{Cb}$ patch which is marked with a red star in Figure 3. (a) Minimum $\mathrm{TB}\left(T_{\min } \mathrm{PD}\right)$ and mean TB $\left(T_{\text {mean }} \mathrm{PD}\right)$; (b) difference in TB over split windows (DSWT) and difference in TB over IR1 and WV (DIWT); (c) cloud area and perimeter; (d) displacement of geometric center and gravitational center; (e) eccentricity (ECCT), shape index of geometric momentum (SIGM), and shape index of the perimeter (SIP); (f) gradient of cloud TB (TOPG), boundary steepness (BS), and standard deviation (STD); (g) cloud life stages (L). L1, L2 ‥ L8 means the same as in Figure 2; (h) cloud growth rate (CGR) and horizontal moving direction (HMDP); (i) vertical moving character of a $\mathrm{Cb}$ patch (VMCP) and horizontal moving speed (HMSP).

addition, some improvement can be made in the near future. For example, some new subpixel cloud tracking approaches, such as the variational echo tracking (VET) and optical flow method, can be applied to improve the accuracy of cloud tracking based on the temporal, spatial, and spectral character of satellites. In addition, considering that the ANN classifier needs numerous samples which depend on the experience of experts, more objective cloud classification methods using time series information of geostationary satellite are needed to improve the algorithm's capability of detecting $\mathrm{Cb}$. Moreover, the time evolution of cloud dynamical features corresponding to the potential of $\mathrm{Cb}$ for heavy rainfall can be analyzed systematically with the extraction of more physically meaningful precipitation parameters. Therefore, efforts are underway by the authors to improve the algorithm by testing more scenarios and we will report our findings in the future.

\section{Conflict of Interests}

The authors declare that there is no conflict of interests regarding the publication of this paper. 


\section{Acknowledgments}

This work was supported by the National Natural Science Foundation of China under Grants 41301379, 41231170, and 41101326 and China Postdoctoral Science Foundation under Grant 2013M541029. The authors would like to thank NSMC (National Satellite Meteorological Center in Beijing) for providing FY2C satellite data. The authors greatly appreciate the careful and insightful suggestions and comments of reviewers which helped to improve the paper and data analysis.

\section{References}

[1] C. C. Henken, M. J. Schmeits, H. Deneke, and R. A. Roebeling, "Using MSG-SEVIRI cloud physical properties and weather radar observations for the detection of $\mathrm{Cb} / \mathrm{TCu}$ clouds," Journal of Applied Meteorology and Climatology, vol. 50, no. 7, pp. 1587$1600,2011$.

[2] S. S. Chen and R. A. Houze Jr., "Diurnal variation and life-cycle of deep convective systems over the tropical Pacific warm pool," Quarterly Journal of the Royal Meteorological Society, vol. 123, no. 538, pp. 357-388, 1997.

[3] S. Moorthi and M. J. Suarez, "Relaxed Arakawa-Schubert: a parameterization of moist convection for general circulation models," Monthly Weather Review, vol. 120, no. 6, pp. 978-1002, 1992.

[4] D. W. Martin and A. J. Schreiner, "Characteristics of West African and East Atlantic cloud clusters: a survey from GATE," Monthly Weather Review, vol. 109, no. 8, pp. 1671-1688, 1981.

[5] D. P. Rowell and J. R. Milford, "On the generation of African squall lines," Journal of Climate, vol. 6, no. 6, pp. 1181-1193, 1993.

[6] I. Velasco and J. M. Fritsch, "Mesoscale convective complexes in the Americas," Journal of Geophysical Research, vol. 92, no. 8, pp. 9591-9613, 1987.

[7] D. Miller and J. M. Fritsch, "Mesoscale convective complexes in the western Pacific region," Monthly Weather Review, vol. 119, no. 12, pp. 2978-2992, 1991.

[8] A. G. Laing and J. M. Fritsch, "Mesoscale convective complexes in Africa," Monthly Weather Review, vol. 121, no. 8, pp. 22542263, 1993.

[9] A. G. Laing and J. M. Fritsch, "The global population of mesoscale convective complexes," Quarterly Journal of the Royal Meteorological Society, vol. 123, no. 538, pp. 389-405, 1997.

[10] W. L. Woodley, C. G. Griffith, J. S. Griffin, and S. C. Stromatt, "The inference of GATE convective rainfall from SMS-1 imagery," Journal of Applied Meteorology, vol. 19, no. 4, pp. 388408, 1980.

[11] M. Williams and R. A. Houze Jr., "Satellite-observed characteristics of winter monsoon cloud clusters." Monthly Weather Review, vol. 115, no. 2, pp. 505-519, 1987.

[12] Y. Arnaud, M. Desbois, and J. Maizi, "Automatic tracking and characterization of African convective systems on Meteosat pictures," Journal of Applied Meteorology, vol. 31, no. 5, pp. 443453, 1992.

[13] H. Feidas and C. Cartalis, "Monitoring mesoscale convective cloud systems associated with heavy storms using meteosat imagery," Journal of Applied Meteorology, vol. 40, no. 3, pp. 491$512,2001$.

[14] L. M. V. Carvalho and C. Jones, "A satellite method to identify structural properties of mesoscale convective systems based on the maximum spatial correlation tracking technique (MASCOTTE)," Journal of Applied Meteorology, vol. 40, no. 10, pp. 1683-1701, 2001.

[15] J. M. Sieglaff, L. M. Cronce, and W. F. Feltz, "Improving satellite-based convective cloud growth monitoring with visible optical depth retrievals," Journal of Applied Meteorology and Climatology, vol. 53, no. 2, pp. 506-520, 2014.

[16] C. Morel, S. Sénési, and F. Autones, "Building upon SAF-NWC products: use of the rapid developing thunderstorms (RDT) product in Météo-France nowcasting tools," in Proceedings of the Meteorological Satellite Data Users' Conference, pp. 248-255, 2002.

[17] C. Goyens, D. Lauwaet, M. Schröder, M. Demuzere, and N. P. M. van Lipzig, "Tracking mesoscale convective systems in the Sahel: relation between cloud parameters and precipitation," International Journal of Climatology, vol. 32, no. 12, pp. 19211934, 2012.

[18] J. M. Sieglaff, L. M. Cronce, W. F. Feltz, K. M. Bedka, M. J. Pavolonis, and A. K. Heidinger, "Nowcasting convective storm initiation using satellite-based box-averaged cloud-top cooling and cloud-type trends," Journal of Applied Meteorology and Climatology, vol. 50, no. 1, pp. 110-126, 2011.

[19] D. A. Vila, L. A. T. Machado, H. Laurent, and I. Velasco, "Forecast and tracking the evolution of cloud clusters (ForTraCC) using satellite infrared imagery: methodology and validation," Weather and Forecasting, vol. 23, no. 2, pp. 233-245, 2008.

[20] R. Dworak, K. Bedka, J. Brunner, and W. Feltz, "Comparison between GOES-12 overshooting-top detections, WSR$88 \mathrm{D}$ radar reflectivity, and severe storm reports," Weather and Forecasting, vol. 27, no. 3, pp. 684-699, 2012.

[21] H. Takahashi and Z. J. Luo, "Characterizing tropical overshooting deep convection from joint analysis of CloudSat and geostationary satellite observations," Journal of Geophysical Research: Atmospheres, vol. 119, no. 1, pp. 112-121, 2014.

[22] P. Mikuš and N. Strelec Mahović, "Satellite-based overshooting top detection methods and an analysis of correlated weather conditions," Atmospheric Research, vol. 123, pp. 268-280, 2013.

[23] K. Bedka, J. Brunner, R. Dworak, W. Feltz, J. Otkin, and T. Greenwald, "Objective satellite-based detection of overshooting tops using infrared window channel brightness temperature gradients," Journal of Applied Meteorology and Climatology, vol. 49, no. 2, pp. 181-202, 2010.

[24] R. D. Roberts, A. R. S. Anderson, E. Nelson et al., "Impacts of forecaster involvement on convective storm initiation and evolution nowcasting," Weather and Forecasting, vol. 27, no. 5, pp. 1061-1089, 2012.

[25] J. R. Mecikalski and K. M. Bedka, "Forecasting convective initiation by monitoring the evolution of moving cumulus in daytime GOES imagery," Monthly Weather Review, vol. 134, no. 1, pp. 49-78, 2006.

[26] R. D. Roberts and S. Rutledge, "Nowcasting storm initiation and growth using GOES-8 and WSR-88D data," Weather and Forecasting, vol. 18, no. 4, pp. 562-584, 2003.

[27] B. J. Burghardt, C. Evans, and P. J. Roebber, "Assessing the predictability of convection initiation in the high plains using an object-based approach," Weather and Forecasting, vol. 29, no. 2, pp. 403-418, 2014.

[28] J. R. Mecikalski, W. M. Mackenzie Jr., M. Koenig, and S. Muller, "Cloud-top properties of growing cumulus prior to convective initiation as measured by meteosat second generation. Part I: infrared fields," Journal of Applied Meteorology and Climatology, vol. 49, no. 3, pp. 521-534, 2010. 
[29] L. A. T. Machado, W. B. Rossow, R. L. Guedes, and A. W. Walker, "Life cycle variations of mesoscale convective systems over the Americas," Monthly Weather Review, vol. 126, no. 6, pp. 16301654, 1998.

[30] L. A. T. Machado and H. Laurent, "The convective system area expansion over Amazonia and its relationships with convective system life duration and high-level wind divergence," Monthly Weather Review, vol. 132, no. 3, pp. 714-725, 2004.

[31] K. I. Hodges and C. D. Thorncroft, "Distribution and statistics of african mesoscale convective weather systems based on the ISCCP meteosat imagery," Monthly Weather Review, vol. 125, no. 11, pp. 2821-2837, 1997.

[32] D. Rosenfeld and C. W. Ulbrich, "Cloud microphysical properties, processes, and rainfall estimation opportunities," in Radar and Atmospheric Science: A Collection of Essays in Honor of David Atlas, vol. 52 of Meteorological Monographs, pp. 237-258, 2003.

[33] A. A. Sinkevich and T. W. Krauss, "Changes in thunderstorm characteristics due to feeder cloud merging," Atmospheric Research, pp. 124-132, 2014.

[34] A. L. Houston and R. B. Wilhelmson, "The impact of airmass boundaries on the propagation of deep convection: a modelingbased study in a high-CAPE, low-shear environment," Monthly Weather Review, vol. 140, no. 1, pp. 167-183, 2012.

[35] P. Mukhopadhyay, M. Mahakur, and H. A. K. Singh, "The interaction of large scale and mesoscale environment leading to formation of intense thunderstorms over Kolkata part I: doppler radar and satellite observations," Journal of Earth System Science, vol. 118, no. 5, pp. 441-466, 2009.

[36] J. F. Weaver and D. Lindsey, "Some frequently overlooked severe thunderstorm characteristics observed on GOES imagery: a topic for future research," Monthly Weather Review, vol. 132, no. 6, pp. 1529-1533, 2004.

[37] P. T. Schlatter, T. W. Schlatter, and C. A. Knight, "An unusual hailstorm on 24 June 2006 in Boulder, Colorado, part I: mesoscale setting and radar features," Monthly Weather Review, vol. 136, no. 8, pp. 2813-2832, 2008.

[38] W. R. Cotton, G. Bryan, and S. C. Van den Heever, "Cumulonimbus clouds and severe convective storms," in Storm and Cloud Dynamics, vol. 99, pp. 315-454, Academic Press, 2010.

[39] T. W. Krauss, A. A. Sin'kevich, R. Burger, N. E. Veremei, Y. A. Dovgalyuk, and V. D. Stepanenko, "Investigation of the impact of dynamic factors on Cb cloud development in Saudi Arabia," Russian Meteorology and Hydrology, vol. 36, no. 10, pp. 643-652, 2011.

[40] R. M. Cintineo and D. J. Stensrud, "On the predictability of supercell thunderstorm evolution," Journal of the Atmospheric Sciences, vol. 70, no. 7, pp. 1993-2011, 2013.

[41] T. Zinner, H. Mannstein, and A. Tafferner, "Cb-TRAM: tracking and monitoring severe convection from onset over rapid development to mature phase using multi-channel Meteosat-8 SEVIRI data," Meteorology and Atmospheric Physics, vol. 101, no. 3-4, pp. 191-210, 2008.

[42] R. L. Bankert, "Cloud classification of AVHRR imagery in maritime regions using a probabilistic neural network," Journal of Applied Meteorology, vol. 33, no. 8, pp. 909-918, 1994.

[43] T. A. Berendes, J. R. Mecikalski, W. M. MacKenzie Jr., K. M. Bedka, and U. S. Nair, "Convective cloud identification and classification in daytime satellite imagery using standard deviation limited adaptive clustering," Journal of Geophysical Research D: Atmospheres, vol. 113, no. 20, Article ID D20207, 2008.
[44] J. Li, W. P. Menzel, Z. Yang, R. A. Frey, and S. A. Ackerman, "High-spatial-resolution surface and cloud-type classification from MODIS multispectral band measurements," Journal of Applied Meteorology, vol. 42, no. 2, pp. 204-226, 2003.

[45] B. A. Baum, V. Tovinkere, J. Titlow, and R. M. Welch, "Automated cloud classification of global AVHRR data using a fuzzy logic approach," Journal of Applied Meteorology, vol. 36, no. 11, pp. 1519-1540, 1997.

[46] Y. Liu, J. Xia, C. Shi, and Y. Hong, "An improved cloud classification algorithm for China's FY-2C multi-channel images using artificial neural network," Sensors, vol. 9, no. 7, pp. 55585579, 2009.

[47] J. Schmetz, K. Holmlund, J. Hoffman et al., "Operational cloud-motion winds from Meteosat infrared images," Journal of Applied Meteorology, vol. 32, no. 7, pp. 1206-1225, 1993.

[48] Y. Hong, K. Hsu, S. Sorooshian, and X. Gao, "Precipitation estimation from remotely sensed imagery using an artificial neural network cloud classification system," Journal of Applied Meteorology, vol. 43, no. 12, pp. 1834-1853, 2004.

[49] L. Xu, S. Sorooshian, X. Gao, and H. V. Gupta, "A cloud-patch technique for identification and removal of no-rain clouds from satellite infrared imagery," Journal of Applied Meteorology, vol. 38, no. 8, pp. 1170-1181, 1999.

[50] Y. Liu, D. G. Xi, Z. L. Li, and C. X. Shi, "Analysis and application of the relationship between cumulonimbus $(\mathrm{Cb})$ cloud features and precipitation based on FY-2C image," Atmosphere, vol. 5, no. 2, pp. 211-229, 2014.

[51] J. A. Augustine and K. W. Howard, "Mesoscale convective complexes over the United States during 1986 and 1987," Monthly Weather Review, vol. 119, no. 7, pp. 1575-1589, 1991. 

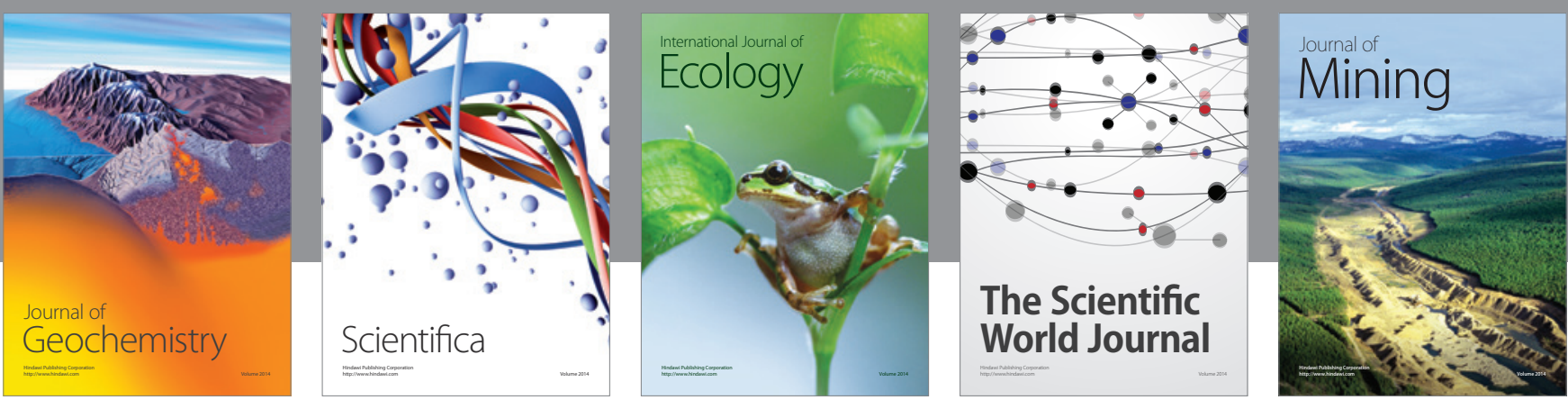

The Scientific World Journal
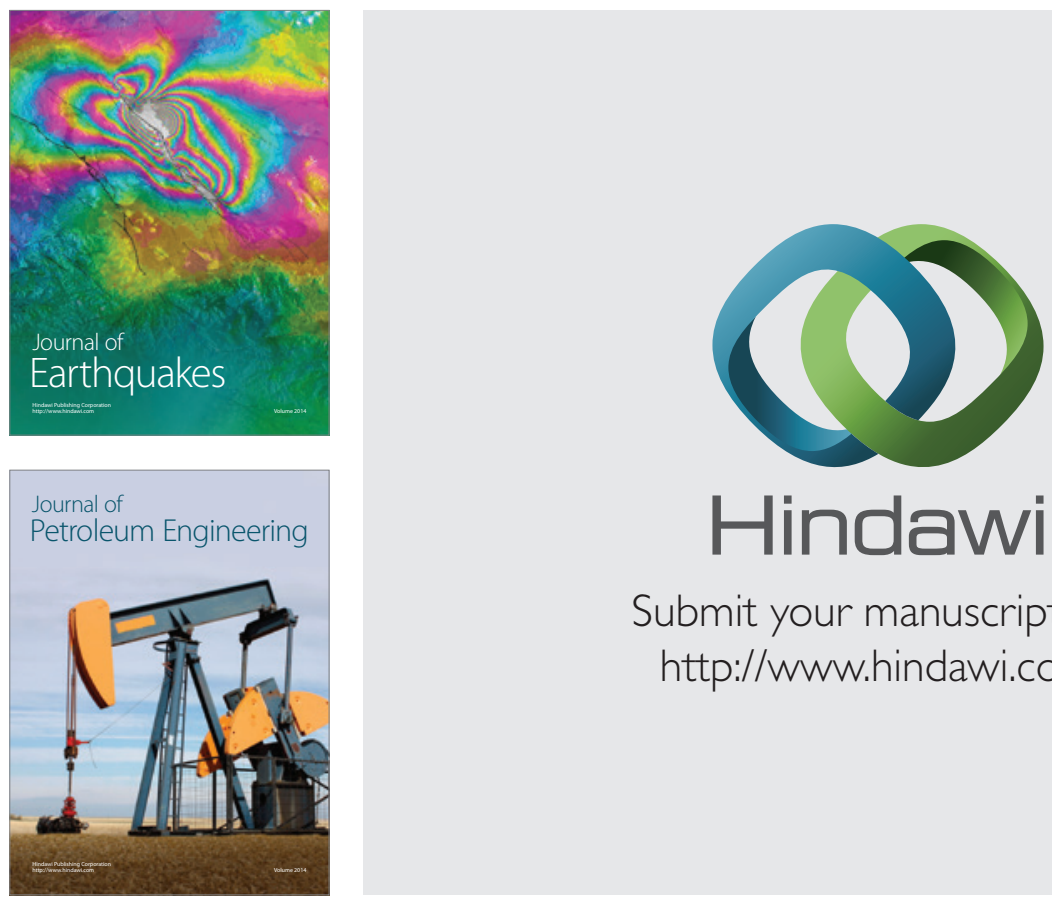

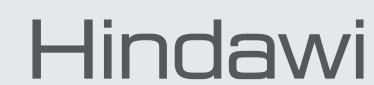

Submit your manuscripts at

http://www.hindawi.com
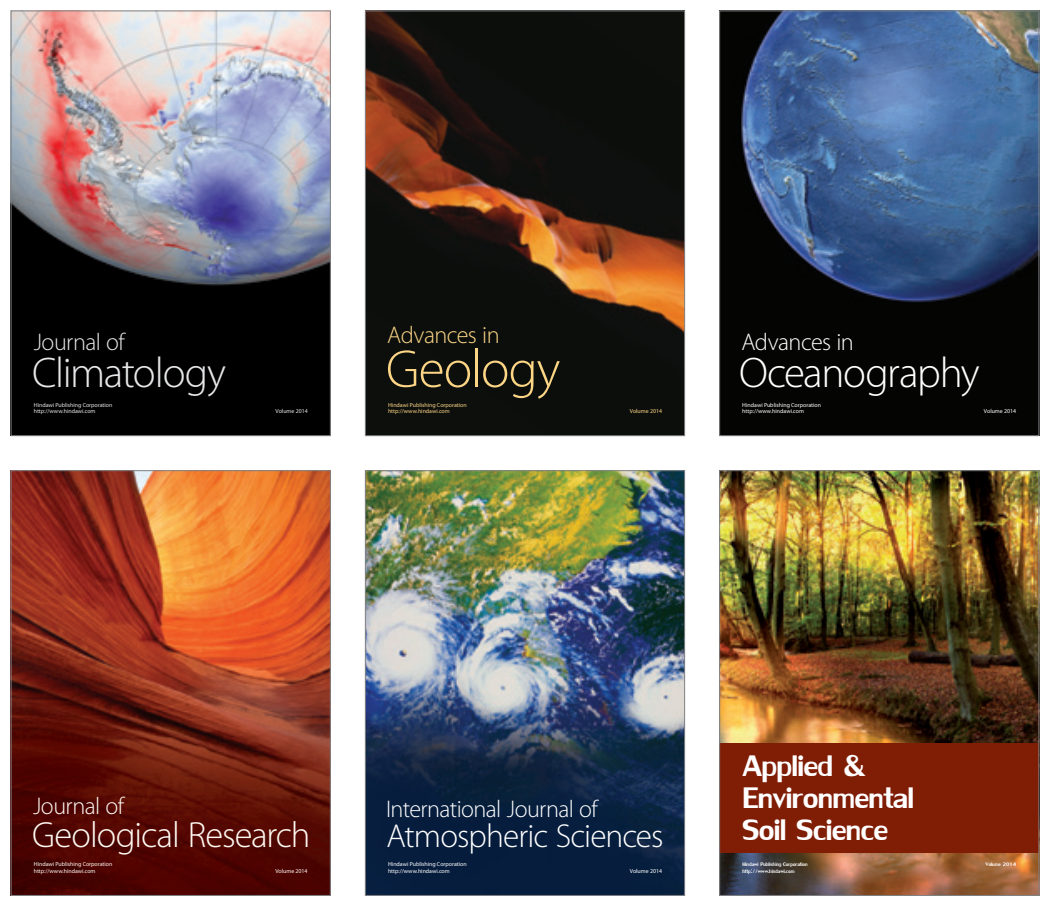
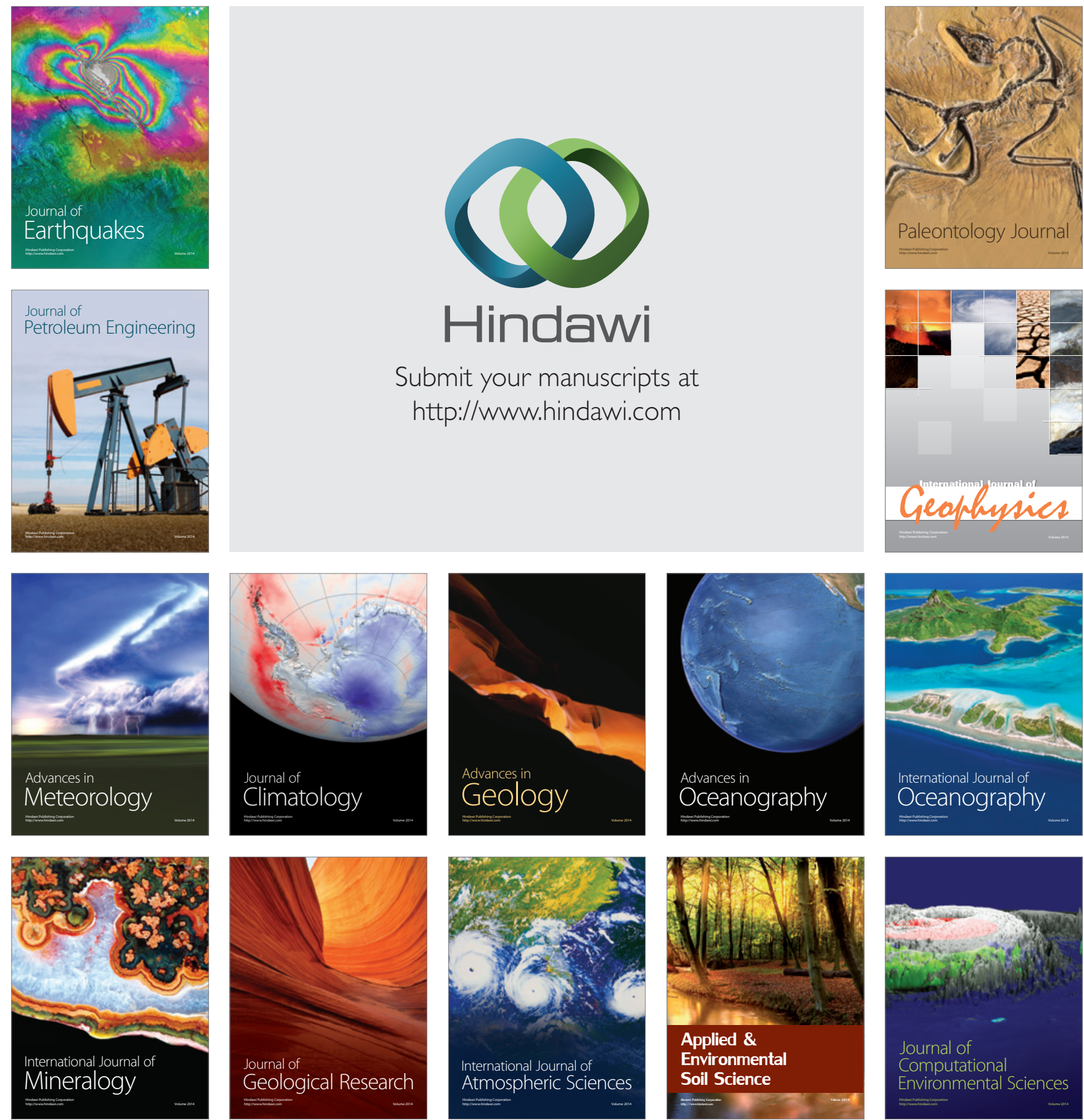